\title{
Firms as Buyers of Last Resort
}

\author{
Harrison Hong \\ Princeton University \\ Jiang Wang \\ MIT and CCFR \\ Jialin $\mathrm{Yu}$ \\ Columbia University
}

First Draft: May 2005

This Draft: April 2007

\begin{abstract}
We develop a model to explore the asset pricing implications of firms being buyers of last resort for their own stocks. Those with more ability to repurchase shares when prices drop far below fundamental value (i.e., less financially constrained ones) should have lower short-horizon return variance (controlling for fundamental variance) than other firms. Using standard proxies for financing constraints such as past repurchases, firm age and the Kaplan and Zingales (1997) index, we find strong support for this predicted relation. Moreover, our theory predicts that this relation should be stronger in environments where repurchases are legally easier to execute. Consistent with our theory, we find that this relation is indeed stronger in the U.S. after 1982 when regulatory reforms lowered the legal cost of conducting repurchases; and among the ten largest stock markets in the world, they are stronger in countries where share repurchases are legally easier to execute.
\end{abstract}

We thank an anonymous referee and Heitor Almeida, Doug Diamond, Diego Garcia, Jeffrey Kubik, Hamid Mehran, Lasse Pedersen, Ronnie Sadka, Jeremy Stein, Sheridan Titman, and seminar participants at the University of British Columbia, Ramon Areces Foundation Conference on Financial Economics, Drexel, New York Federal Reserve Bank, Princeton-New York Federal Reserve Bank Liquidity Conference, Pompeau Fabra, and Econometric Society Meeting, for a number of helpful comments. 


\section{Introduction}

In this paper, we explore the idea of firms being buyers of last resort for their own stocks. The phrase "buyers of last resort" is inspired by the vast literature started by Bagehot (1873) on the role of central banks as lenders of last resort for their economies. Just as central banks make funds available to markets in times of crises, a firm can provide liquidity to its investors, when no one else will, by repurchasing shares of its own stock. Such firm intervention not only influences the price of individual stocks, but also has macroeconomic consequences. For instance, many companies quickly bought back a large fraction of their shares after the stock market crash of 1987. Via the coordination of stock exchanges, a large number of firms also announced repurchase programs immediately after the events of September 11, 2001. These anecdotes suggest that companies were and can be important liquidity providers.

There is evidence beyond these anecdotes that firms intervene in their stocks when prices move significantly away from fundamental value. In a survey by Brav, Graham, Harvey, and Michaely (2004) of 384 CFOs, the most popular response for why firms repurchase stocks ( $86.6 \%$ of those surveyed agree) is that their stock is cheap relative to its true value. Using large panel datasets, several studies confirm the relative importance of valuation (low price-to-book ratios or poor past returns) as a motive for this financial decision (see e.g., Dittmar (1999) and Stephens and Weisbach (1998)). In addition, other works find positive drift in abnormal returns following announcements of firms conducting repurchases (Ikenberry, Lakonishok and Vermaelen $(1995,2000))$ ). For instance, Ikenberry, Lakonishok and Vermaelen (1995) find for the U.S. stock market that the average abnormal four-year buy-and-hold return measured after the initial announcement is 12.1 percent. They also find that for low price-to-book stocks, companies more likely to be repurchasing shares because of undervaluation, the average abnormal return is 45.3 percent. For repurchases announced by high-price-to book stocks where undervaluation is less likely to be an important motive, no positive drift in abnormal returns is observed. Ikenberry, Lakonishok and Vermaelen (2000) find similar evidence for Canada and in addition that trades also appear linked to price movements as managers buy more shares when prices fall. 
In sum, these findings suggest that repurchases are consistent with firms intervening opportunistically much like speculators or market-makers would after price falls significantly below fundamental value and earning long-run abnormal returns for these trading activities. ${ }^{1}$ There is also a similar set of evidence suggesting that firms issue equity when they perceive their shares to be over-valued (see Baker, Ruback and Wurgler (2004) for a review of this evidence).

We develop a model to explore the effects of firms being buyers of last resort for their stocks. We extend the Grossman and Miller (1988) model to allow firms to intervene in their own stocks when liquidity shocks are sufficiently large. ${ }^{2}$ We are agnostic about the source of these shocks leading to deviations of price from fundamental value. We will call these liquidity shocks, though we are equally comfortable with identifying them as demand shocks due to, say, shifts in investor sentiment. While the Grossman-Miller model is typically applied to returns of very short-horizons, we think of our extension as applying to longer-horizons in which shocks have to be big enough (accumulate over a long enough time) for the firm to profitably intervene. ${ }^{3}$

Our first prediction is that those firms with less ability to intervene should prices deviate too far from fundamental value ought to have a higher short-horizon return variance controlling for an appropriately scaled version of fundamental or long-horizon return variance. Intuitively, firms with low-intervention ability end up with greater deviations of price from fundamental value and hence greater reversals as liquidity shocks are assumed to mean revert over long enough horizons. This means a higher short-horizon controlling for fundamental or long-horizon return variance (since longterm return variance corresponds to fundamental variance in our model) compared to high-intervention ability firms.

\footnotetext{
${ }^{1}$ It is also possible that a firm buys back its own shares due to information that only the firm has. This, however, seems less likely for two reasons. First, repurchases often follow a fall in share prices, i.e. they are predictable given past returns or valuation ratios. Second, repurchases are announced publicly, and yet price adjustments take several years.

${ }^{2}$ Firms are not in the business of being market makers. They only intervene when the liquidity shocks are sufficiently large. We model this by assuming that firms have a higher cost of participating in the market than other traders.

${ }^{3}$ Recent evidence by Coval and Stafford (2005) and Frazzini and Lamont (2005) confirm that liquidation of stocks by mutual funds lead the prices of these stocks to be depressed relative to fundamental value for long-periods of time, suggesting the possibility of firms profitably buying shares to profit from this deviation, i.e. the frictions imagined in the Grossman-Miller framework apply beyond the very shorthorizon setting to which the model is typically applied.
} 
We test this prediction by measuring the ability of different firms in the crosssection to be buyers of last resort for their own stocks and relating this to the stock's return variance. Our basic premise is that the capability of the firm to be the buyer of last resort for its own stock or to intervene more generally depends on the extent to which it is financially constrained. In particular, firms that are equity dependent are unlikely to execute repurchases. As such, the first prediction of our model is that more financially constrained firms ought to have a higher short-horizon return variance controlling for fundamental variance.

To avoid data-mining biases, we use standard measures of financing constraints from the recent corporate finance literature. In particular, we use the measures advocated by Kaplan and Zingales (1997), Lamont, Polk and Saa-Requejo (2001), Baker, Stein and Wurgler (2003). ${ }^{4}$ The first and closest to our theory is stock repurchases (relative to dollar turnover or market capitalization) since our model emphasizes the ability of firms to execute share repurchases to counter liquidity shocks. A broader rationale is that since repurchases and investments are competing uses of funds, firms facing severe financing constraints would do less buy backs. Our second measure is firm age, which is based on the premise that younger firms have a harder time getting access to public debt markets. Corporate-finance considerations also suggest that equity-dependent firms will tend to have high leverage (either market or book), low cash balances and pay less dividends. So our third measure is the Kaplan-Zingales index and various versions of it, which take into account whether a firm is paying dividends, leverage, cash balances, cash flow, and a firm's Tobin's Q (i.e. its market-to-book ratio). ${ }^{5}$

Using data from 1963 to 2005, we begin our empirical investigation by confirming our premise that financially constrained firms are less likely to intervene in their stocks. Not surprisingly, our three sets of financing constraint measures are quite correlated. Nonetheless, we find that all three measures have incremental predictive power on firm repurchase activity: firms that have done past repurchases, older firms and

\footnotetext{
${ }^{4}$ Note that a number of the variables in these three recent papers are used in earlier work on financing constraints such as Gertler and Gilchrist (1994) and Fazzari, Hubbard and Petersen (1988).

5 As we explain below, firm leverage and market-to-book may be difficult to interpret in certain contexts, so we will end up controlling for these two firm characteristics in some of our regressions below.
} 
lower $\mathrm{KZ}$ index firms are more likely to execute repurchases. As such, our empirical analysis below features all three proxies.

We then test our first prediction in the U.S. stock market by using cross-sectional variation to see whether short-horizon return variance (anywhere from daily to quarterly returns) is higher for financially constrained firms, controlling for fundamental or longhorizon return variance, which we take to be either the variance of return-on-equity (computed along the lines suggested by Cohen, Polk and Vuolteenaho (2006)) or the variance of three-year returns. ${ }^{6}$ The results are similar so we feature the variance of return-on-equity. Consistent with our model, we find that our measures of financing constraints all come in with the right sign and are statistically and economically significant, regardless of the frequency at which we measure short-horizon return variance. For instance, a two-standard deviation increase in $\mathrm{KZ}$ (more financially constrained) leads to an increase in weekly return variance that is anywhere from $30 \%$ to $40 \%$ of the standard deviation of weekly return variance depending on the version of the $\mathrm{KZ}$ index used.

We then attempt to rule out a number of alternative hypotheses for these findings. Indeed, one natural explanation for why financially constrained firms have higher shorthorizon variance controlling for fundamental variance might have to do with leverage and distress. While we can control to some degree for firm leverage and other covariates (such as firm size, etc...), it is impossible to fully rule out the plausibility of alternative hypotheses such as the leverage/distress hypothesis or other forms of omitted variables with this approach.

As such, we turn to our second prediction, which cuts more decisively in favor of our intervention-repurchase effect: the documented relation between variance and constraint ought to be stronger in environments (regimes) where repurchases are legally easier to execute. Our premise is that the relationship between financing constraints (e.g. firm age) and variances is due to the ability of firms to repurchase in the first place (so that our financing constraint measures accurately capture the true cost of intervention). So in regimes where repurchases are legally costly to execute or perhaps even illegal, we

\footnotetext{
${ }^{6}$ An important caveat is that return on equity (ROE) and long-horizon return variance are noisy measures of fundamental volatility.
} 
should not find an effect since the true cost of intervention for a firm is not simply financing constraints.

More technically, our identification strategy is to consider a difference-indifference (diff-in-diff) estimate of the effect of financing constraints on short run variance controlling for fundamental variance. Loosely, we first estimate the crosssectional relation between constraints and variances (the first difference) in the difficultto-repurchase regime. We take for granted that this relation may not be due to our intervention-repurchase hypothesis but perhaps to some other mechanisms. We then estimate the same relationship during the easy-to-repurchase regime (the second difference). The difference in these two differences is attributed to our interventionrepurchase effect on the basis that the other mechanisms such as leverage risk ought not to vary with legal regimes regarding repurchases. We are expecting a stronger relationship in the easy-to-repurchase regime than the difficult-to-repurchase regime.

We use two sources of exogenous variation to better identify our theory. The first is the regulatory reform in the U.S. stock market in 1982 in the form of SEC Rule 10b-18 that encouraged repurchases. While share repurchases had always been legal in the U.S., companies still worried about class-action lawsuits accusing them of manipulating their stock prices with repurchases. The passage of SEC Rule 10b-18 shielded firms from such lawsuits. This law is attributed by many for the rise of share repurchases since (see, e.g., Grullon and Michaely (2002)). Since the price effects arise from firms being able to legally execute repurchases in the first place, our theory predicts that the (cross-sectional) relations between financing constraints and return variances ought to be stronger after 1982 when the legal cost of doing repurchases went down. ${ }^{7}$ We find that this is indeed the case---our effect is indeed stronger (both economically and statistically) after the regulatory reforms regardless of the financing constraint measures we use.

The second source of variation we use to better identify our theory comes from the cross-section of stock markets around the world. Survey evidence from Kim, Schremper and Varaiya (2004) on stock repurchases across the ten largest stock markets, U.S., Japan, U.K., France, Germany, Canada, Italy, the Netherlands, Switzerland and

\footnotetext{
${ }^{7}$ More specifically, in periods in which repurchases are difficult or illegal, a firm's financing constraint under-estimates the true cost of intervention and hence the relation between financing constraint measures and firm return variances will be weaker during these periods. A similar statement applies across countries.
} 
Hong Kong, indicates that these countries fall naturally into three groups in terms of legal ease of repurchases: easy, medium and difficult. Our time period of analysis is 19931998. During this period, the easy group comprises of the U.S., U.K. and Canada, and the difficult group comprises of France and Germany (in which repurchases were basically illegal). The other five countries in the medium category are more heavily regulated than the U.S. but repurchases were not illegal during this period. We do not have a consistent set of repurchase and firm age data across countries but are able to construct the $\mathrm{KZ}$ measures and use the latter in our analysis.

Remarkably, we find, consistent with our theory and following the same logic (diff-in-diff estimate) as for the US regulatory experiment, that the predicted relations between the $\mathrm{KZ}$ measures and return volatility are stronger in the easy group than in the medium group and stronger in the medium group than in the difficult group. Importantly, for the difficult group, the relation between $\mathrm{KZ}$ and return volatility is actually of the wrong sign. For the medium group where repurchases are possible, we get the right sign and the relation is marginally significant in some cases. For the easy group, we get results very similar to those of the U.S. as expected. Again, these differences and the ordering of magnitude of the coefficients across these three groups are very economically and statistically significant.

These two tests form the crux of our paper. It is important to emphasize that without them, it would be impossible for us to distinguish between our intervention story from the alternative leverage story. As such, we make sure that our tests are robust. Toward this end, we perform diagnostics associated with these diff-in-diff estimates (as suggested by Bertrand, Duflo and Mullainathan (2002)) such as randomizing where to put the breaks for the US data and which countries to put in the different groups for the international data. If our findings are spurious, then we should see the same diff-in-diff results as above using these randomization procedures. This is not the case. The randomization procedures yield results far different from our diff-in-diff estimates. Moreover, these procedures also allow us to confirm that our standard errors are reasonable. We also perform a number of additional robustness checks such as rerunning our regressions as a pooled panel with clustered standard errors, trying different 
specifications and different measures of financing constraints and fundamental variance. And in each instance, we obtain remarkably consistent results.

Finally, we further strengthen the case for our firm intervention effect by relating the skewness of stock returns to financial constraints. With an additional assumption that financing constraint is likely to affect stock repurchases and not issuances, our model delivers a third prediction---that those less financially constrained firms with more capacity to repurchase shares quickly after a market crash (e.g. crash of 1987) should have more positively skewed short-horizon (e.g. daily) returns. We discuss the merits of the assumption that there is an asymmetry in the likelihood or cost of intervention below. Nonetheless, we do find support for this additional prediction. Though skewness is more difficult to measure than volatility and our parameters are estimated less precisely than in the case of volatility, we do find that financially unconstrained firms have more positively skewed daily returns and that this relationship is stronger after 1982, when repurchases became legally easier to execute.

Our paper is novel in exploring the effects of firm intervention (particularly of firms being buyers-of-last resort for their own stock) on stock returns and liquidity. Our findings further develop the connection between corporate finance (e.g. the financing constraints literature) and asset pricing/market micro-structure (see Stein (1996) and Baker and Wurgler (2002)). Our paper introduces the firm as an important set of participants in the market and is of general interest since the model and its implications developed here apply equally well in other contexts such as the Federal Reserve Bank or the government more generally being lenders-of-last resort for the aggregate market. ${ }^{8}$

Our paper proceeds as follows. We develop a simple model to analyze the effect of firm intervention on stock return variance in Section 2. We describe the dataset in

\footnotetext{
${ }^{8}$ One might also wonder why we do not extend our model to develop implications for expected returns and relate them to financing constraints. One potential implication is that financing constrained firms have higher expected returns precisely because they are less liquid. There is already a large literature that looks at the relation between liquidity and expected returns (see, e.g., Amihud and Mendelson (1986) and Brennan and Subrahmanyam (1996)) and some find that more illiquid stocks indeed have higher expected returns. Additional regressions of returns on financing constraints would be difficult to interpret since there are mechanisms other than liquidity through which financing constraints might affect expected returns (e.g. financially constrained firms undertake less of certain kinds of investments, thereby giving the company a different risk profile).
} 
Section 3 and the main empirical results in Section 4. We conclude in Section 5. All proofs are in the Appendix.

\section{Model}

In this section, we develop a simple model which captures how a firm's intervention in the market in response to large liquidity shocks affects the price behavior of its own stock. The framework we use is similar to that of Grossman and Miller (1988), in which liquidity shocks to a subset of investors give rise to temporary shifts in the demand of a stock. ${ }^{9}$ These shifts in demand cause temporary deviations in the stock price, given limited market making capacity in the market. When the firm intervenes in the market for its own stock, it effectively serves as a market maker together with the other market makers. We want to use the term market-maker in the broadest possible sense---the firm acts a speculator (buyer) of last resort in its own stock in conjunction with other speculators in the market such as hedge funds. Thus, when a firm is less constrained and more willing to act as a market maker, the liquidity for its own stock also increases.

We do not explicitly model the overall objective of the firm (i.e. the agent running the firm). We simply assume the reduced form that the firm intervenes when prices deviate significantly from fundamental value. One justification is that accommodating liquidity shocks can sometimes be a profitable activity because of frictions outlined in Grossman and Miller (1988). Suppose investors are heterogeneous in facing liquidity shocks. If some investors want to cash out for liquidity reasons, other existing investors (the firm) can provide liquidity by buying their shares if there are not enough market makers around. ${ }^{10}$

\subsection{Set-up}

\footnotetext{
9 Here, we take the liquidity shock as exogenous, as in Grossman and Miller (1988). In a recent paper, Huang and Wang (2006) show that these liquidity shocks can arise endogenously in the presence of market fricitons.

${ }^{10}$ Another justification is based on agency theory in which the manager gets compensated for a high stock price and counters liquidity shocks so that the stock price more accurately reflects his ability (i.e. fundamentals). See Stein (1996) and Baker, Ruback and Wurgler (2004) for additional justifications.
} 
Suppose there are three dates: $t=0,1,2$. A stock is traded in a competitive market, whose cash flow is $\widetilde{v}_{t}$ at $t=1,2$ and $\widetilde{v}_{t}$ is an i.i.d. normal random variable with a mean of zero and a variance of $\sigma_{v}^{2}$. At $t=1, \widetilde{x}$ shares of the stock is dumped into the market by a set of investors for liquidity reasons, where $\tilde{x}$ is a normal random variable (thus can be negative) with a mean of zero and a variance of $\sigma_{x}^{2}$.

There is a set of market makers in the market who can absorb the liquidity shock. For now we assume that their population is $\mu$ and their risk tolerance is $\tau$. The total risk tolerance of market makers is $\tau_{M}=\mu \tau{ }^{11}$ Moreover, the firm can also intervene in the market of its own shares when short-term liquidity shocks move the price of the stock far away from its fundamental value. In deciding on its intervention policy, the firm has an effective risk tolerance of $\tau_{F}$ and faces a cost to intervene. For convenience, we assume that both the market makers and the firm are initially endowed with no shares of the stock. $^{12}$

Let $\theta_{F}$ denote the position the firm takes in the stock market to moderate its share price. We assume that the intervention cost is linear in the size of the position:

$$
c\left(\theta_{F}\right)= \begin{cases}\kappa_{+}\left|\theta_{F}\right|, & \theta_{F}>0 \\ 0, & \theta_{F}=0 \\ \kappa_{-}\left|\theta_{F}\right|, & \theta_{F}<0 .\end{cases}
$$

The intervention cost assumed above is intended to capture several characteristics of a firm's intervention behavior. First, the cost to intervene prevents the firm from trading its own shares at all times. Instead, it intervenes only when price deviations caused by the liquidity shock is sufficiently large. Second, the threshold and the strength of the intervention may both depend on the firm's ability to adjust its financial position. In the

\footnotetext{
${ }^{11}$ These market makers are needed to set the price under normal circumstances when the firm is not intervening.

${ }^{12}$ It may seem artificial to assume that the firm has zero shares of its own stock. Other than simplicity, the motivation for such an assumption is as follows. A firm's intervention in the market is an activity separate from its usual business operations. Thus, it may treat it separately when considering its merit, in particular, its risk-return trade-off. Our results do not depend on this simplifying assumption.
} 
case of share repurchase, for example, the firm's ability to intervene in the market clearly depends on how constrained it is in amassing the funds needed. In the case of seasoned equity issues, its ability depends on the cost to issue new equity. The linear form of the cost function makes the cost dependent on the size of the intervention.

The proportionality coefficients, $\kappa_{+}$and $\kappa_{-}$, reflect the firm's ability to intervene. Moreover, the cost coefficient is in general different between share repurchases and sales, reflecting the fact that constraints and costs can be asymmetric between these two operations. In particular, we will assume that $\kappa_{-}>\kappa_{+}$. That is, other things equal, it is easier for the firm to repurchase its shares from the market than issuing new shares.

In the remainder of the paper, we will further assume that $\kappa_{-}=\infty$. Thus, the firm's intervention only takes the form of share repurchase. Also, we set $\tau_{F}=\infty$, i.e., the firm is risk neutral. These two assumptions help to simplify the analysis, but are not critical to the results. To simplify notation, we let $\kappa=\kappa_{+}$.

\subsection{Equilibrium and Price Behavior}

We now consider the market equilibrium in the simple model described above and the resulting stock price. Let $\widetilde{p}_{t}$ denote the stock price at $t$, after payoff $\widetilde{v}_{t}, t=0,1,2$ (with $\tilde{v}_{0}=0$ ). No arbitrage insures that the stock price at $t=2$ is simply 0 , i.e., $\tilde{p}_{2}=0$. At $t=1$, a liquidity shock $\tilde{x}$ occurs. Both the market makers and the firm will attempt to accommodate the liquidity shock. Their desire to provide liquidity depends on three factors: the current price of the stock, the payoff when they unload the position in the future, and their risk tolerance. By assuming that the payoff next period is $\widetilde{v}_{2}$, we are effectively assuming that the liquidity providers can unload their positions at $\widetilde{v}_{2}$. The uncertainty in $\tilde{v}_{2}$ reflects the risk they have to bear to make the market.

Theorem 1: At $t=1$, the equilibrium stock price is

$$
\tilde{p}_{1}=-\left(\sigma_{v}^{2} / \tau_{M}\right) \min \left(\tilde{x}, x^{*}\right),
$$

where $x^{*}=\left(\tau_{M} / \sigma_{v}^{2}\right) \kappa \geq 0$. At $t=0$, the equilibrium stock price is given by 


$$
p_{0}=\mathrm{E}_{0}\left[\widetilde{p}_{1} e^{-\widetilde{p}_{1}^{2} / 2}\right] / \mathrm{E}_{0}\left[e^{-\widetilde{p}_{1}^{2} / 2}\right]
$$

where $\mathrm{E}_{0}[\cdot]$ denotes the expectation at time 0 . From the solution to the equilibrium, we observe the following. In absence of any liquidity shock, the stock price at $t=1$ is also zero, which reflects the fundamental value of the stock. Note that the expected payoff of the stock is assumed to be zero. Although the realized payoff is risky, market makers and the firm bear no risk in absence of any liquidity shocks since their initial holdings are zero. Consequently, the price of the stock is also zero. When there is a liquidity shock $\tilde{x}$, however, market makers and the firm have to bear the risk of the stock if they accommodate the shock. Naturally, the price has to adjust to compensate them for the risk. The price adjustment depends on the risk of the stock $\sigma_{v}^{2}$, the size of the shock $\tilde{x}$ and the overall risk tolerance of the market. ${ }^{13}$

When the liquidity shock $\tilde{x}$ is smaller than $x^{*}$, the firm does not intervene and the liquidity shock is fully absorbed by market makers. The price is determined by their risk tolerance. Although the stock price deviates from its fundamental, the size of the deviation, given by $-\left(\sigma_{v}^{2} / \tau_{M}\right) \tilde{x}$, is not large enough to trigger the firm to intervene. When the liquidity shock $\tilde{x}$ is larger than $x^{*}$, however, the price deviation becomes sufficiently large for the firm to step in. Given that the firm is assumed to be risk neutral, it will absorb the liquidity shock alone and the deviation of the stock price from its fundamental is limited at the threshold level $-\left(\sigma_{v}^{2} / \tau_{M}\right) x^{*}$. The maximum deviation is determined by $\kappa$, the firm's intervention cost.

From the equilibrium price process, we obtain several properties of the stock's returns. For simplicity, we consider the dollar returns on the stock:

$$
\widetilde{r}_{t} \equiv \widetilde{v}_{t}+\widetilde{p}_{t}-\tilde{p}_{t-1}
$$

\footnotetext{
13 Please see, among others, Campbell, Grossman and Wang (1993) and Grossman and Miller (1988) for a more elaborate analysis of this.
} 
where $t=1,2$. Let $\sigma^{2}(n)$ denote the stock return variance over $n$ periods, where $n=1,2$. Thus, we have $\sigma^{2}(1)=\operatorname{Var}\left[\widetilde{r}_{1}\right]=\operatorname{Var}\left[\widetilde{r}_{2}\right]$ and $\sigma^{2}(2)=\operatorname{Var}\left[\widetilde{r}_{1}+\widetilde{r}_{2}\right]$. We then have $\sigma^{2}(2)=2 \sigma_{v}^{2}$, where $\sigma_{v}^{2}$ gives the variance of the fundamental, and

$$
\sigma^{2}(1)=\sigma_{v}^{2}+\operatorname{Var}\left[\tilde{p}_{t}\right]
$$

where $\operatorname{Var}\left[\tilde{p}_{t}\right]$ denotes the short-run price variation due to liquidity shocks. In general, $\operatorname{Var}\left[\tilde{p}_{t}\right]$ depends on the variance of liquidity shocks $\sigma_{x}^{2}$, the variance of the fundamental $\sigma_{v}^{2}$, the risk tolerance of market makers $\tau_{M}$, and more importantly the firm's cost of intervention $\kappa$. In particular, we have the following result:

Proposition 1: Short-horizon return variance is greater than long-horizon or fundamental variance. Controlling for long-horizon or fundamental variance, shorthorizon return variance increases with the cost of intervention $\kappa$ (i.e. financing constraint), i.e., $\partial \sigma^{2}(1) / \partial \kappa>0$.

Firms with lower intervention cost are likely to participate in the market to support its share price. As a result, we will see less deviation in its stock price from its fundamentals in response to liquidity shocks and the short-horizon stock returns will exhibit less variance holding fixed fundamental variance.

Given the documented persistence of financing constraints, our empirical analysis utilizes cross-sectional firm variation in the cost of intervention. The dependent variable is naturally a firm's short horizon variance and the independent variables are fundamental variance and the various proxies for a firm's financing constraints. We also include other controls, which we detail below. The predicted relationship from Proposition 1 is that all else equal, the higher a firm's financing constraint, the higher its short-horizon variance controlling for fundamental variance.

Since the price effects arise from firms being able to legally execute repurchases in the first place, in periods or regimes in which repurchases are difficult or illegal, a 
firm's financing constraint under-estimates the true cost of intervention and hence the relation between financing constraint measures and firm return variances will be weaker during these periods. Hence our theory predicts:

Proposition 2: The cross-sectional relationship between financing constraints and return variances (controlling for fundamental variance) ought to be stronger in the period or regime in which the legal cost of doing repurchases is cheaper.

As we detail below, we will test Proposition 2 using two sources of exogenous variation: legal reforms in the United States through time and cross-sectional variation in legal regimes across an international sample.

\section{Data}

Our data on U.S. firms come from the Center for Research in Security Prices (CRSP) and COMPUSTAT. From CRSP, we obtain daily and monthly stock returns, closing stock prices, shares outstanding, and share trading volume for NYSE, AMEX and NASDAQ stocks. From COMPUSTAT, we obtain annual information on a variety of accounting variables. To be included in our sample, a firm must first have the requisite financial data on CRSP and COMPUSTAT. We include only common stocks (CRSP item SHRCD=10 or 11) listed on NYSE / AMEX / NASDAQ. We follow other studies of the U.S. market using market-to-book ratios in excluding firms with book value less than ten million and firms with one-digit SIC codes of 6, which are in the financialservices industry. We will calculate long-horizon return variances using six-year windows and exclude stocks with less than seventy-two monthly return observations in the six-year window.

Our data on firms for the other nine countries come from the COMPUSTAT GLOBAL database, which begins in 1993. From this database, we obtain monthly closing prices, dividends, shares outstanding and trading volume, which only allow us to calculate variables such as return variances at monthly or lower frequencies. Moreover, we are only able to obtain a subset of the accounting variables that are available in the U.S. Namely, this database does not have information on stock repurchases nor are we 
able to obtain firm age. Fortunately, we do have enough data to construct various versions of the Kaplan-Zingales index of financing constraints.

\section{A. Return Variance Measures}

For each year, we begin in the U.S. stock market by calculating for each stock its cash flow variance (CVAR) according to Cohen, Polk and Vuolteenaho (2006) using sixyear windows. Cash flow is measured by the logarithm of $R O E_{t}$ - ratio of clean-surplus earnings $\left(B E_{t}-B E_{t-1}+D_{t}^{\text {gross }}\right)$ to beginning-of-the-period book equity $\left.\left(B E_{t-1}\right)\right)^{14}$ Dividend $D_{t}^{\text {gross }}$ is from COMPUSTAT data item 21. Firm i's cash flow variance in year $t$ is calculated using six annual data from year $t$ to $t+5$. This variable is denoted by $\mathrm{CVAR}_{\text {it.. }}$ We then calculate for each stock the variance of 3-year log returns using overlapping six-year windows. For instance, firm i's 3-year return variance in 1963 (the first year for this variable) is calculated using annual data from 1963 to 1968. Using two three-year non-overlapping returns (i.e. the log return from the beginning of 1963 to the end of 1965, the return from the beginning of 1966 to the end of 1968), we calculate this 3-year return variance and annualize it by dividing it by three. This variable is denoted

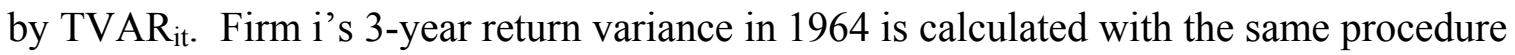
using data from 1964 to 1969, and so forth for all the other years in our sample. The last year that we can calculate TVAR is 2000 since our dataset ends in 2005.

For each observation of CVAR and TVAR, we then calculate the corresponding shorter horizon return variances. For instance, for firm i in 1963, we calculate the variance of daily returns (denoted by $\mathrm{DVAR}_{\mathrm{it}}$ ), weekly returns (denoted by WVAR $\mathrm{R}_{\mathrm{it}}$ ), monthly returns $\left(\mathrm{MVAR}_{\mathrm{it}}\right.$ ), and quarterly returns (denoted by $\mathrm{QVAR}_{\mathrm{it}}$ ), using data from 1963 to 1968 ---all these variances are calculated using non-overlapping returns and are

\footnotetext{
${ }^{14}$ Book equity $B E_{t}$ is defined as stockholders' equity (COMPUSTAT data item 216) plus balance sheet deferred taxes (COMPUSTAT data item 74) and investment tax credit (data item 208) (if available), plus post-retirement benefit liabilities (data item 330) (if available) minus the book value of preferred stock. Depending on availability, we use redemption (data item 56), liquidation (data item 10), or par value (data item 130) (in that order) for the book value of preferred stock. If stockholders' equity is unavailable from COMPUSTAT, we measure stockholders' equity as common equity (data item 60) plus the book value of preferred stock. If common equity is not available, we compute stockholders' equity as the book value of assets (data item 6) minus total liabilities (data item 181), all from COMPUSTAT.
} 
annualized. We repeat the same procedure for 1964 using data from 1964 to 1969 and so forth for all the other years in the sample.

For the other nine markets during the period of 1993-2003, we calculate the same individual stock return variance measures, except that we are unable to calculate any daily or weekly numbers.

\section{B. Financing Constraint Proxies}

Our financial constraint proxies for U.S. companies are the following. The first financing constraint proxy is REPO/VOLUME, a firm's repurchases (COMPUSTAT Item 115 minus preferred stock reduction divided by daily dollar volume. Preferred stock reduction is from the first difference of COMPUSTAT item 10. We will also consider REPO/MKT, a firm's repurchases divided by market capitalization. These two measures follow nicely from our theory since the ability of a firm to stabilize its stock price depends both on how much resources it has relative to how many shares it might have to stabilize. Dollar volume and market capitalization capture the potential size of liquidity shocks hitting a firm. We winsorized REPO/VOLUME and REPO/MKT at $1 \%$ and $99 \%$ level. The results are similar when the raw REPO/VOLUME and REPO/MKT are used. Firm AGE is defined as the year that we are considering minus the first year that that firm has price data in CRSP monthly returns file, which starts in 1925 .

Our third financing constraint proxy is the KZ index. Following Lamont, Polk and Saa-Requejo (2001) and Baker, Stein and Wurgler (2003), we construct the fivevariable $\mathrm{KZ}$ index for each firm-year as the following linear combination:

$\mathrm{KZ}_{\mathrm{it}}=-1.002 \mathrm{CF}_{\mathrm{it}} / \mathrm{A}_{\mathrm{it}-1}-39.368 \mathrm{DIV}_{\mathrm{it}} / \mathrm{A}_{\mathrm{it}-1}-1.315 \mathrm{C}_{\mathrm{it}} / \mathrm{A}_{\mathrm{it}-1}+3.139 \mathrm{BLEV}_{\mathrm{it}}+0.283 \mathrm{Q}_{\mathrm{it}}(6)$

where $C F_{i t} / A_{i t-1}$ is cash flow (Item 14+Item 18) over lagged assets (Item 6); DIV $V_{i t} / A_{i t-1}$ is cash dividends (Item 21+Item 19) over assets; $C_{i t} / A_{i t-1}$ is cash balances (Item 1) over start-of-the-year book assets (Item 6); book leverage, denoted by BLEV $\mathrm{it}_{\mathrm{it}}$, which is total debt divided by the sum of total debt and book equity ((Item 9+Item 34)/(Item 9+Item 34+Item 216))---this is measured at fiscal year-end; and Tobin's $Q$ is the market value of equity (price times shares outstanding from CRSP) plus assets minus the book value of 
equity (Item 60+Item 74) all over assets. We winsorize the ingredients of the index before constructing it.

We will also use a modified version of the $\mathrm{KZ}$ index that differs from the original score in that it excludes a measure of leverage and Tobin's Q:

$$
\mathrm{KZ3}_{\mathrm{it}}=-1.002 \mathrm{CF}_{\mathrm{it}} / \mathrm{A}_{\mathrm{it}-1}-39.368 \mathrm{DIV} \mathrm{V}_{\mathrm{it}} / \mathrm{A}_{\mathrm{it}-1}-1.315 \mathrm{C}_{\mathrm{it}} / \mathrm{A}_{\mathrm{it}-1}
$$

KZ3 makes more sense than KZ for our purposes because highly levered firms may have higher short-horizon volatility for a given fundamental volatility if leverage ratios change in a particular manner over time and Q may proxy for both investment opportunities and mis-pricing. To the extent that we want to rule out alternative explanations related to mechanical leverage effects and mis-pricing, we will drop leverage and Q from the KZ index. $^{15}$ It turns out that there is little difference in our results between using KZ3 or KZ. So we will feature KZ3 in the main results and provide the results relating to $\mathrm{KZ}$ in the robustness section. We view the use of these proxies as simply an effort to restrict ourselves to these previously nominated variables, so as to avoid data mining. The sample period is 1971-2005 for REPO/MKT and REPO/VOLUME and is 1963-2005 for other US variables.

For international companies, the corresponding data item numbers from COMPUSTAT GLOBAL are the following. $\mathrm{CF}_{\text {it }} / \mathrm{A}_{\mathrm{it}-1}$ is cash flow (Item 11+Item 32) over lagged assets (Item 89); $\mathrm{DIV}_{\mathrm{it}} / \mathrm{A}_{\mathrm{it}-1}$ is cash dividends (Item 36+Item 35) over assets; $\mathrm{C}_{\mathrm{it}} / \mathrm{A}_{\mathrm{it}-1}$ is cash balances (Item 60) over start-of-the-year book assets (Item 89); book leverage, denoted by $\mathrm{BLEV}_{\text {it, }}$ is (Item 106+Item 94)/(Item 106+Item 94+Item 135); and Tobin's $\mathrm{Q}$ is the average market cap plus assets minus the book value of equity (Item 146+Item 105) all over assets.

\section{Other Variables}

\footnotetext{
${ }^{15}$ A word of warning regarding cash and leverage as proxies for financing constraints is that constrained firms should endogenously try to save more cash (see Almeida, Campello and Weisbach (2004)) and perhaps save some debt capacity for the future (thus having lower leverage). Almeida, Campello and Weisbach (2004) show that the KZ index, which loads heavily on cash and leverage, might sort firms crosssectionally in an unintuitive way. Hence, we want to also rely on other, perhaps more exogenous, proxies such as firm age to make inferences.
} 
The other variables that we use are very familiar and do not merit much discussion. LOGSIZE $E_{i t}$ is the log of firm i's stock-market capitalization at the end of year t. TURNOVER ${ }_{i t}$ is the average monthly share turnover in stock $\mathrm{i}$ - defined as shares traded divided by shares outstanding - over year t. RET $_{\text {it }}$ is the average monthly return on stock i, also measured over the 12-month period t. LOGMB $_{\text {it }}$ is the $\log$ of firm i's market cap at the end of year $t$ divided by its book value in year $t$. We also use market leverage which is denoted by $M E_{\text {it }}$, which is the same as BLEV except that we replace Item 216 with a firm's market capitalization at the end of that calendar year. We can calculate these variables for U.S. and international companies. We also use exchange dummies downloaded from CRSP.

\section{Summary Statistics}

The summary statistics for the variables used in the financing constraints related regressions are presented in Table 1 . We report the time series average of cross-sectional means and standard deviations. We start with the statistics for the U.S. stock market and then report the analogous numbers for the other countries in turn. We first present the statistics for annualized return variances at different horizons. The summary statistics for the other countries are similar in magnitude. We then present the summary statistics for our financing constraint proxies. We have checked that these statistics are similar to those found in other studies such as Baker, Stein and Wurgler (2003). Finally, we present the summary statistics for the other variables.

\section{Empirical Results}

A. Correlatedness of Financing Constraint Proxies and Likelihood of Initiating Repurchase Programs

We analyze the relation between our financing constraint proxies in Table 2 and their ability to predict repurchases. In Panel A, we calculate the contemporaneous correlation between the various proxies in a given year. We find that older firms and firms with lower values of KZ's (less constrained) are more likely to have high REPO/VOLUME or REPO/MKT values and older firms are more likely to have lower $\mathrm{KZ}$ scores. In other words, these financing constraint proxies are correlated. Most of 
these correlations are statistically significant. The results are largely the same regardless of these different measures, so we plan to feature REPO/VOLUME and leave REPO/MKT for the robustness checks.

In Panel B, we focus on what determines (predicts) whether a firm executes repurchases. While this issue has been covered in previous papers, we just want to point out that one can predict repurchases using past repurchases, firm age and the $\mathrm{KZ}$ indices. To this end, we gather additional data on which firms initiate a stock buy-back program in a given year from the SDC Database, which reports for each year the firms that have obtained authorization from their board to initiate repurchases. The SDC data spans the period of 1993-2005. The variable REPINITIATE $\mathrm{i}_{\mathrm{i}, \mathrm{t}}$ equals one if a firm i initiates a repurchase program in year $t$ and zero otherwise. About $14.32 \%$ of firms in a given year initiate a new repurchase program.

Importantly, we find in column (1) of Panel B that firms with higher values of REPO/VOLUME in year t-1 are more likely to initiate repurchase programs in year $t$. The coefficient in front of REPO/VOLUME is 0.0035 with a t-statistic of 7.27. This means that a two-standard increase in REPO/VOLUME leads to an increase in the likelihood of repurchase next year by about $0.15(0.0035 \times 2 \times 21.6)$. Compared to the unconditional mean probability of initiation (which is 0.1432), this is a substantial increase in the probability of initiation (over twice as likely). Similarly, in column (2), we find that older firms (AGE) are more likely to initiate a repurchase program and as are lower KZ3 index value firms (less constrained) (see column (3)). These effects are also economically sizeable (and of similar magnitudes) and statistically significant. In column (4), we do a horse race between each of these constraint proxies and find that each has incremental forecasting power for repurchases next year. Indeed, the coefficients in front of each of these three proxies are fairly similar to what we obtained when we considered each one of them separately (in columns (1)-(3)), except that the coefficient on AGE is attenuated (now 0.0014 but still statistically significant).

In Panel C, rather than using the REPINITIATE as the dependent variable, we use REPO/VOLUME. The results are similar. So the results in Panels B and C clearly show that these financing constraint proxies do predict the likelihood of future repurchases and hence verifies the premise of our empirical work. Moreover, we have also separately 
checked that these results do indeed hold for the year of ' 87 crash, which was a particularly relevant source of anecdotal motivation for our work. In sum, these findings are consistent with the idea that financially constrained firms are less likely to execute repurchases.

\section{B. Return Variance and Financing Constraints, U.S. Stock Market}

We begin by looking at whether financially constrained firms have a higher shorthorizon return variance controlling for fundamental variance (Proposition 1). To this end, we will implement the following cross-sectional regression specification:

STVAR $_{i t}=a_{0 t}+a_{1 t} *$ CONSTRAINT $_{i t-1}+a_{2 t} *$ CVAR $_{i t}+a_{3 t}$ LOGSIZE $_{i t-1}+a_{4 t} *$ MLEV $_{i t-1}+$ $\mathrm{a}_{5 \mathrm{t}}{ }^{*}$ LOGMB $_{\mathrm{it}-1}+\mathrm{a}_{6 \mathrm{t}}{ }^{*}$ RET $_{\mathrm{it}-1}+\mathrm{a}_{7 \mathrm{t}} *$ TURNOVER $_{\mathrm{it}-1}+$ INDUSTRYDUMMIES $_{\mathrm{it}-1}+$ EXCHANGEDUMMIES $_{\mathrm{it}-1}+\varepsilon_{\mathrm{it}}, \quad \mathrm{i}=1, \ldots, \mathrm{N}$

where STVAR it $_{\text {is }}$ short-horizon return variance (including DVAR, WVAR, MVAR, QVAR), and CONSTRAINT is a proxy for the degree to which a firm is financing constrained (including REPO/VOLUME, AGE, and KZ3). CVAR, the variance of return on equity, is a noisy measure of fundamentals. This is an important caveat when it comes to interpreting our findings. We try to deal with this using long-horizon return variance but this is not a perfect solution either as we discuss below. Here, $\varepsilon_{\mathrm{it}}$ stands for a generic error term that is uncorrelated with all other independent variables. The coefficient of interest is $\mathrm{a}_{1 \mathrm{t}}$, which captures the relation between financing constraints and short-horizon return variance controlling for the firm's fundamental variance and a host of other firm characteristics (LOGSIZE, MLEV, LOGMB, RET, TURNOVER, INDUSTRYDUMMIES and EXCHANGEDUMMIES). ${ }^{16}$ We then take the estimates from these annual regressions and follow Fama and MacBeth (1973) in taking their time series means and standard deviations to form our overall estimates of the effects of financing constraints on the short-horizon return variance. ${ }^{17}$

\footnotetext{
${ }^{16}$ The industry dummies use the Fama and French (1997) 48 industry classification.

${ }^{17}$ Instead of having TVAR on the right hand side, one could have one of the short-term variances, e.g. look at how the ratio of DVAR (daily variance) to WVAR (weekly variance) varies with financing constraints. We do not expect to find much since this ratio is close to one to begin with and firms do not intervene at
} 
In addition to CVAR which is suggested by theory, we include MLEV and LOGMB as control variables in equation (8). While these two variables are thought of as financing constraint proxies in their own right, they may also affect short-horizon return variance for other reasons. For instance, highly-levered firms may have a higher shorthorizon return variance given its fundamental variance if a firm's debt-to-equity ratio declines over time. And high market-to-book companies may be more volatile because they are growth stocks. As a result, we take the conservative stance in seeing to what extent our financing constraint proxies hold up even after controlling for firm leverage and market-to-book. In addition, we include a firm's size, past returns and past turnover as control variables. These variables are meant to pick up potential differences in investor sentiment across firms.

The results are presented in Table 3. The dependent variable in Panel A is DVAR, the variance of daily returns. In column (1), the measure of financing constraint is REPO/VOLUME. Notice that the coefficient in front of REPO/VOLUME is negative $(-0.0007$ with a t-statistic of 2.11), which is consistent with our model. A two-standard deviation increase in REPO/VOLUME leads to a decline in short-horizon return variance of $-0.03(-0.0007 \times 2 \times 21.6)$, which is $12 \%(-0.03 / .2427)$ of the cross-section standard deviation of short-horizon return variance.

Notice that the coefficients on the control variables all come in with expected signs (see Chen, Hong and Stein (2001)). DVAR increases with higher fundamental variance CVAR, firm leverage MLEV, firm market-to-book LOGMB and stock turnover TURNOVER and decreases with LOGSIZE and RET. The coefficients in front of these variables are all statistically significant. These coefficients do not change much as we utilize different financing constraint proxies in columns (2)-(3). The only thing to note are that the coefficient in front of MLEV is no longer significant when we use the KZ3 index as financing constraint proxies.

In column (2), we consider our second financing constraint proxy, firm age. The coefficient in front of AGE is negative and statistically significant. A two-standard deviation increase in firm age lowers DVAR by about 3\% as a fraction of the standard

such short horizons. We have run these alternate regressions and found as expected little effect of financing constraints in this set-up. 
deviation of DVAR. In column (3), we consider the KZ3 index in explaining DVAR. The coefficient in front of KZ3 is positive and statistically significant---higher KZ3 index firms, which are more financially constrained, end up with higher return variance. A two-standard deviation increase in KZ3 leads to an increase in DVAR that is $24 \%$ of the standard deviation of DVAR.

In Panel B, we re-run the same regressions but consider return variances at different horizons, from weekly return variance to quarterly return variance. We only report the coefficient in front of the financing constraint variables for brevity. Notice that the signs in front of all the financing constraints all go the right way and the coefficients in front of financing constraint proxies are always statistically and economically significant. A straightforward calculation of economic significance in Panel B also indicates that the economic magnitudes are roughly similar to that of Panel A. For instance, for weekly return variance, the implied economic magnitudes are $15 \%$ for REPO/VOLUME, $10 \%$ for AGE, and $30 \%$ for KZ3. In sum, the results in Table 3 strongly support the first prediction of our model that more financially constrained firms end up with higher short-horizon return variance controlling for fundamental variance.

\section{Relations between Financing Constraints and Variances, US Stock Market}

\section{Before and After Regulatory Reforms of 1982}

While we can control to some degree for firm leverage and other covariates, it is impossible to distinguish between our firm intervention effect against other alternatives

with this approach. As such, we turn to the first of our two sources of what can arguably be deemed as exogenous variation to better identify our theory: the major regulatory reform in the U.S. stock market in 1982 that encouraged repurchases. Without these variations, we would not be able to distinguish between our intervention story from a leverage alternative for financially constrained firms having higher return relative to fundamental variance. While share repurchases had always been legal in the U.S., companies still worried about class-action lawsuits accusing them of manipulating their stock prices with repurchases. The passage of the SEC 10b-18 in 1982 shielded firms from such lawsuits. This law is attributed by many for the rise of share repurchases since (see, e.g., Grullon and Michaely (2002)). Since the price effects arise from firms being 
able to legally execute repurchases in the first place, in periods in which repurchases are difficult or illegal, a firm's financing constraint under-estimates the true cost of intervention and hence the relation between financing constraint measures and firm return variances will be weaker during these periods. Hence our theory suggests that the (crosssectional) relations between financing constraints and return variances ought to be stronger after 1982 when the legal cost of doing repurchases went down.

As we alluded to in the introduction, our identification strategy is to consider a difference-in-difference (diff-in-diff) estimate of the effect of financing constraints on short-run variance controlling for fundamental variance. We first estimate the crosssectional relation between constraints and variances (the first difference) in the difficultto-repurchase regime. We take for granted that this relation may not be due to our intervention-repurchase hypothesis but some other stories. We then estimate the same relationship during the easy-to-repurchase regime (the second difference). The difference in these two differences is attributed to our intervention-repurchase effect on the basis that the other stories such as leverage risk ought not to vary in such a manner. We are expecting a stronger relationship in the easy-to-repurchase regime than the difficult-torepurchase regime.

To see if this is the case, we take the regression coefficients in front of CONSTRAINT from the annual Fama-MacBeth regressions in Table 3 and regress these coefficients on a constant and a dummy variable AFTER82 that equals 1 if the year is after 1982 and zero otherwise. ${ }^{18}$ Since higher values of REPO/VOLUME and AGE should lead to lower variance, we expect that the coefficients in front of these two variables should become more negative after 1982. Since higher values of KZ3 index should lead to higher variance, we expect the coefficients in front of KZ3 to become more positive after 1982.

The results are presented in Table 4. In Panel A, we report the results for the variance regressions. We first report the results for the DVAR regressions, then WVAR, and so on until QVAR. Notice that for REPO/VOLUME, the coefficient in front of AFTER82 is negative as predicted for each of these variance regressions. In each case,

\footnotetext{
${ }^{18}$ Our definition of post-1982 is the first six year window (1983-1988) during which the dependent variables, the variances, are calculated. We have also tried skipping from 1976-1981 to 1982-1987 and the results are largely similar.
} 
the coefficient in front of AFTER82 is statistically significant. Moreover, the economic difference is large. Importantly, the results are similar for AGE and KZ3. In each and every case, the results are economically and statistically significant---consistent with our hypothesis, the relationship between constraint and variance is much stronger after 1982 .

In Panel B, we report diagnostics associated with these diff-in-diff estimates as suggested by Bertrand, Duflo and Mullainathan (2002). The details of these diagnostics are given in the Appendix. But essentially, we take the data (cross-sectional regression coefficients from each year) and randomly shuffle them and then re-run the time series regression in which we pick a break-point (analog to the AFTER1982) that yields us the same number of observations before and after. In other words, we randomly re-order the data but still pretend as if the coefficients are still in chronological sequence and run the AFTER82 regression. It is as if the AFTER82 dummy is randomly assigned. If there is true information in the break using the 1982 regulatory reform, regression results using the re-shuffled data should be different from those in Panel A.

Specifically, we conduct 1000 reshuffles. In each iteration, we generate a continuous random variable $\pi_{t}$ (any continuous distribution will do and we choose uniform distribution) for each year and sort years into ascending orders of $\pi_{t}$. We then pick a cut-off value so that years with $\pi_{t}$ less than the cut-off value are assigned $A F T E R 82_{t}=0$ and the rest of years are assigned $A F T E R 82_{t}=1$. The cut-off value is chosen so that the number of years with $A F T E R 82_{t}=1$ is the same as that in the actual estimation.

Notice that these pseudo-AFTER82 regressions yield essentially a zero coefficient on average in front of the AFTER82 dummy. The t-statistics are also zero on average. This suggests that our AFTER82 break is not spurious. Moreover, we can use the saved coefficients from these 1000 random shuffles and use the standard deviation of these estimates to calculate alternative standard errors for our coefficients in Panel A. This is the randomization inference in Bertrand, Duflo and Mullainathan (2002). These tstatistics are fairly similar to the t-statistics obtained in Panel A.

We have also conducted additional analyses to check the robustness of these findings. These results are available on request from the authors. We summarize them 
here for brevity. First, we know that aggregate repurchases increased dramatically directly as a result of the 1982 regulatory change (Grullon and Michaely (2002)). Hence, we could use aggregate repurchases as a proxy for the cost of doing repurchases, i.e. use aggregate repurchases (sum of all dollar repurchases across firms in each year) instead of our AFTER82 dummy in our time series test. Indeed, this might make sense if the aggregate level of repurchases captured the slow adoption of repurchases as an intervention tool after 1982. But of course, this is not the only reason for why repurchases increased. Hence, we still think it is cleaner to use the AFTER82 dummy in our time series tests.

Nonetheless, we took the time series of coefficients in front of financial constraint and regress them (OLS) on a constant and the time series of aggregate repurchases. We find that the coefficients in front of REPO/VOLUME (repurchases called by volume) and AGE become more negative as aggregate repurchases increase, while the coefficients in front of KZ3 become more positive with aggregate repurchases. These results are consistent with our AFTER82 tests which show that the intervention effect has become stronger as repurchases have been legalized. Moreover, to the extent that we think that the reforms of 1982 led to an increase in repurchases, we can instrument for aggregate repurchases using the AFTER82 dummy. The results are very consistent with those of the OLS and support our intervention story becoming more prominent after 1982.

In addition, we re-run our AFTER82 tests by controlling for the average (crosssectional) cashflow variance (CVAR) each year. Cashflow variances are increasing over time and might spuriously lead to our AFTER82 findings to the extent that they contribute to higher price volatility over time. Since the cashflow variance measures are exogenous in our model, we can control for them on the right hand side of our AFTER82 tests. Our AFTER82 results are fairly robust to including these controls.

We have also included as controls the average (cross-sectional) price variances each year (e.g., average of MVAR). Our results are similar to those using average CVAR as a control. The only caveat for this exercise is that price volatility is a dependent variable in our regressions from which we extract the time series of coefficients in front of our constraint measures, i.e. it is an endogenous variable in our model since our model says repurchases affects the level of price volatility. As a result, including price volatility 
as a control in our AFTER82 tests may be problematic from an interpretational perspective.

\section{International Evidence}

But even out AFTER82 test has its limitations. Namely, we cannot distinguish our regulatory regime change effect from other time trends that might also be driving our AFTER82 findings. As such, we next examine the second source of variation associated with the variation in the legal ease of repurchases across countries. Survey evidence from Kim, Schremper and Varaiya (2004) on stock repurchases across the ten largest stock markets, U.S., Japan, U.K., France, Germany, Canada, Italy, the Netherlands, Switzerland and Hong Kong, suggest that these countries can be placed into three groups in terms of legal ease of repurchases: easy, medium and difficult. During the period of 1993-1998, the sample of our analysis, the easy group comprises of the U.S., U.K. and Canada, and the difficult group comprises of France and Germany (in which repurchases were basically illegal). ${ }^{19}$ The other five countries in the medium category are more heavily regulated than the U.S. but repurchases were not illegal during this period. ${ }^{20}$

Using the same logic as for the regulatory reforms in the U.S., our theory suggests that the predicted relations between financing constraints and return volatility are stronger in the easy to repurchase group than in the medium difficulty group and stronger in the medium group than in the difficult to repurchase group. To test this prediction, we run a pooled regression of the ten countries in our sample analogous to those in Tables 3 and 4. In running this pooled regression, we allow the effect of each of the control variables to vary by country and the effect of the financing constraint to vary by our three groups of countries.

The regression specification is the following:

$$
\begin{aligned}
& \text { STVAR }_{\mathrm{it}}=\left(\mathrm{d}_{1} * \mathrm{US}_{\mathrm{i}}+\mathrm{d}_{2} * \mathrm{CN}_{\mathrm{i}}+\mathrm{d}_{3} * \mathrm{UK}_{\mathrm{i}}+\ldots+\mathrm{d}_{10} * \mathrm{HK}_{\mathrm{i}}\right)+\mathrm{c}_{1} * \text { CONSTRAINT }_{\mathrm{it}-1} * \text { EASY }_{\mathrm{i}} \\
& +\mathrm{c}_{2} * \text { CONSTRAINT }_{\mathrm{it}-1} * \text { MEDIUM }_{\mathrm{i}}+\mathrm{c}_{3} * \text { CONSTRAINT }_{\mathrm{it}-1} * \text { DIFFICULT }_{\mathrm{i}}+\text { CVAR }_{\mathrm{it}}
\end{aligned}
$$

\footnotetext{
${ }^{19}$ Share repurchases were illegal in France and Germany until 1998, whereas share repurchases have been legal in US, UK and Canada for a long period of time.

${ }^{20}$ Share repurchases became legal in Japan in 1994, in Switzerland in 1992, in Hong Kong in 1991 and as for Italy and the Netherlands, share repurchases were legal by the early nineties.
} 


$$
\begin{aligned}
& *\left(\mathrm{e}_{1} * \mathrm{US}_{\mathrm{i}}+\mathrm{e}_{2} * \mathrm{CN}_{\mathrm{i}}+\mathrm{e}_{3} * \mathrm{UK}_{\mathrm{i}}+\ldots+\mathrm{e}_{10} * \mathrm{HK}_{\mathrm{i}}\right)+\mathrm{LOGSIZE}_{\mathrm{it}-1} *\left(\mathrm{f}_{1} * \mathrm{US}_{\mathrm{i}}+\mathrm{f}_{2} * \mathrm{CN}_{\mathrm{i}}+\mathrm{f}_{3} * \mathrm{UK}_{\mathrm{i}}\right. \\
& \left.+\ldots+\mathrm{f}_{10} * \mathrm{HK}_{\mathrm{i}}\right)+\mathrm{MLEV}_{\mathrm{it}-1} *\left(\mathrm{~g}_{1} * \mathrm{US}_{\mathrm{i}}+\mathrm{g}_{2} * \mathrm{CN}_{\mathrm{i}}+\mathrm{g}_{3} * \mathrm{UK}_{\mathrm{i}}+\ldots+\mathrm{g}_{10} * \mathrm{HK}_{\mathrm{i}}\right)+\mathrm{LOGMB}_{\mathrm{it}-} \\
& { }_{1} *\left(\mathrm{~h}_{1} * \mathrm{US}_{\mathrm{i}}+\mathrm{h}_{2} * \mathrm{CN}_{\mathrm{i}}+\mathrm{h}_{3} * \mathrm{UK}_{\mathrm{i}}+\ldots+\mathrm{h}_{10} * \mathrm{HK}_{\mathrm{i}}\right)+\mathrm{RET}_{\mathrm{it}-1} *\left(\mathrm{k}_{1} * \mathrm{US}_{\mathrm{i}}+\mathrm{k}_{2} * \mathrm{CN}_{\mathrm{i}}+\mathrm{k}_{3} * \mathrm{UK}_{\mathrm{i}}+\right. \\
& \left.\ldots+\mathrm{k}_{10} * \mathrm{HKi}\right)+\mathrm{TURNOVER}_{\mathrm{it}-1} *\left(\mathrm{~m}_{1} * \mathrm{US}_{\mathrm{i}}+\mathrm{m}_{2} * \mathrm{CN}_{\mathrm{i}}+\mathrm{m}_{3} * \mathrm{UK}_{\mathrm{i}}+\ldots+\mathrm{m}_{10} * \mathrm{HK}_{\mathrm{i}}\right)+\varepsilon_{\mathrm{it}}
\end{aligned}
$$

where STVAR is one of the short-term variance measures, US, CN, UK, ..., HK are country dummies, CONSTRAINT is either KZ3 or KZ, EASY equals 1 when the country is US, Canada or UK and zero otherwise, MEDIUM equals 1 when the country is Japan, Italy, Switzerland, Netherlands or Hong Kong and zero otherwise, DIFFICULT equals 1 when the country is Germany or France and zero otherwise. The remaining variables are the same as from the regressions in Tables 3 and $4 .^{21}$ The t-statistics are Newey-West (1987), though we have also clustered standard errors at the country level and found similar results.

The coefficients for CONSTRAINT*EASY $\left(c_{1}\right)$, CONSTRAINT*MEDIUM $\left(c_{2}\right)$ and CONSTRAINT*DIFFICULT $\left(c_{3}\right)$ measure the effect of the various financing constraint variables on variance for each of these three groups. We then test that the coefficient in front of CONSTRAINT*EASY is greater than the coefficient in front of CONSTRAINT*MEDIUM, which is greater than the coefficient in front of CONSTRAINT*DIFFICULT.

The results are reported in Table 5. We do not have a consistent set of repurchase and firm age data across countries but are able to construct the $\mathrm{KZ}$ measures and use the latter in our analysis. Panel A reports the results for variances. Notice that for MVAR and QVAR, the effect of constraints on variance is larger in the easy group than the medium group and larger in the medium group than the difficult group. The results are not only economically large but statistically significant. For instance, the coefficient for MVAR on EASYxKZ3 is 0.0302 compared to 0.0045 for MEDIUMxKZ3 compared to 0.0361 for DIFFICULTxKZ3. This ordering is consistent for the other measures of

\footnotetext{
${ }^{21}$ Industry dummies are omitted from these regressions because industry classifications vary greatly by country.
} 
variances. In Panel $\mathrm{C}$ below, we find that this ordering is in fact statistically significant. The results for the KZ are given in Panel B. They are similar to those of KZ3.

In Panel $\mathrm{C}$, we report the upper-bound on the p-value for testing the inequalities regarding the effect of financing constraints on variances: $c_{1}>c_{2}>c_{3}{ }^{22}$ For both KZ3 and $\mathrm{KZ}$, the predicted inequality is statistically significant. In sum, we conclude that the international evidence is strongly supportive of our second prediction.

Finally, in Panel D, we first randomly reshuffle each country into the EASY, MEDIUM and DIFFICULT groups so that the total number of countries in each group equals that in Panels A and B and then run the regression specification in Panels A and B on the reshuffled data---1000 reshuffles are repeated. Panel D reports the average coefficients and average Newey-West t-statistics of EASY x CONSTRAINT, MEDIUM $x$ CONSTRAINT and DIFFICULT $x$ CONSTRAINT in the regressions using the reshuffled data. What we expect is the coefficients in front of the various constraint measures for each group to be roughly the same, i.e. we should not see the ordering in the size of the coefficients across the three groups of countries as we have in Panels A and B.

Indeed, notice that the coefficient for CONSTRAINT is positively significant on average across the EASY, MEDIUM and DIFFICULT groups. More importantly, the coefficients are roughly the same size across the three groups of countries (with the coefficient in the MEDIUM group being slightly larger than the rest and the coefficient in the coefficient in the DIFFICULT groups slightly smaller than the rest). Since the MEDIUM group has the most countries and the DIFFICULT group the least, this means the U.S., U.K. and Canada are now more likely to be in the MEDIUM group and least likely to be in the DIFFICULT group across the 1000 simulations. This would explain the slight differences in coefficients. The important thing to note is that the ordering of EASY $>$ MEDIUM $>$ DIFFICULT found in Panels A and B are absent on average using shuffled data which suggests the findings in Panels A and B are genuinely due to the cut according to ease-of-repurchase. Also reported is the fraction of reshuffles such that the differences in the coefficient of constraint between EASY and MEDIUM group and

\footnotetext{
${ }^{22}$ The upper-bound on the $p$-value is derived in the following manner. Let $p$ denote the $p$-value of the joint test that $c_{1}>c_{2}>c_{3}$, which is defined as $\mathrm{p}=1-\operatorname{Prob}\left(\mathrm{c}_{1}>\mathrm{c}_{2}\right.$ and $\left.\mathrm{c}_{2}>\mathrm{c}_{3}\right)$. The $\mathrm{p}$-value can be rewritten as: $\mathrm{p}=1-\left[\operatorname{Prob}\left(\mathrm{c}_{1}>\mathrm{c}_{2}\right)+\operatorname{Prob}\left(\mathrm{c}_{2}>\mathrm{c}_{3}\right)-\operatorname{Prob}\left(\mathrm{c}_{1}>\mathrm{c}_{2}\right.\right.$ or $\left.\left.\mathrm{c}_{2}>\mathrm{c}_{3}\right)\right]=\left[1-\operatorname{Prob}\left(\mathrm{c}_{1}>\mathrm{c}_{2}\right)\right]+\left[1-\operatorname{Prob}\left(\mathrm{c}_{2}>\mathrm{c}_{3}\right)\right]-1+\operatorname{Prob}\left(\mathrm{c}_{1}>\right.$ $c_{2}$ or $\left.c_{2}>c_{3}\right)$. Since $\operatorname{Prob}\left(c_{1}>c_{2}\right.$ or $\left.c_{2}>c_{3}\right)-1$ is always less than zero, it follows that $p \leq 1-\operatorname{Prob}\left(c_{1}>c_{2}\right)+1-$ $\operatorname{Prob}\left(\mathrm{c}_{2}>\mathrm{c}_{3}\right)$.
} 
between MEDIUM and DIFFICULT group are larger than those in panel A and B. This occurs in only less than $2.5 \%$ of the reshuffles which is in line with the p-values computed in Panel C.

\section{E. Robustness Checks}

In this section, we perform a number of robustness checks. We begin by taking the baseline regression specification in Table 3 and consider a number of permutations. First, there is the worry that the standard errors from the Fama-MacBeth regressions are not appropriate. So rather than estimating it using Fama-MacBeth methodology, we run a pooled regression and cluster the standard errors by both firm and time as in Thompson (2006). The right hand side variables are the same as in Table 3 except with the addition of year dummies. The results are reported in Panel A. They are similar to those in Table 3 and the t-statistics are if anything larger. This alleviates any concerns regarding statistical inference for our results. Indeed, we have also re-calculated the standard errors for our cross-country regressions using both clustering by country and Thompson standard errors and our results are still significant. These results are available on request from the authors.

Next, in Panel B, we work with log of the variances rather than the level of the variances themselves. In other words, we take the logs of DVAR, WVAR, MVAR, QVAR, and CVAR and then re-run the regressions using logs of variances everywhere there is a level for the variances. Working with logs can alleviate concerns about outliers and gives us a sense of robustness to functional forms. The results are similar to those in Table 3. In Panel C, we use three-year stock return variance instead of the cashflow variance (CVAR) as a control. The results are also similar to those in Table 3.

In Panel D, we look at the behavior of the two other measures of financing constraints, REPO/MKT instead of REPO/VOLUME and KZ instead of KZ3. For brevity, we only report the results analogous to those in Table 4, which looks at the

relationship between these constraint measures and variance before and after the regulatory reforms of 1982. The results are largely similar to those in Table 4. 
In Panels E and F, we apply the robustness checks using the log specification and replacing CVAR with TVAR to the international regression specification of Table 5. Again, the results are similar and very robust.

\section{F. Return Skewness and Financing Constraints, U.S. Stock Market}

In sum, our international evidence helps buttress the AFTER82 evidence and these two findings in sum strongly distinguish our intervention hypothesis from other alternatives. Here, we try to make our case even stronger by testing an additional prediction regarding return skewness and financial constraints. Under the assumption that repurchases are more likely to be affected by financing constraints as opposed to issuances (e.g., $\kappa_{-}=\infty$ in the model), we get an additional testable implication, which is that financially unconstrained firms should have more positively skewed returns.

Before presenting our results, we note that the reasonableness of this assumption depends on horizons. At short horizons, it would be difficult for firms to stabilize equity prices using issuances. In contrast, firms with more capacity to repurchase shares quickly after a market crash (e.g. crash of 1987) should have more positively skewed shorthorizon returns. At long horizons, when there is potentially built up demand for a stock, even financially constrained firms can issue equity to take advantage of high prices. And so we would not expect there to be any skewness implications at long horizons.

This is an interesting empirical question and confirmation of a relation between return skewness and financial constraints would further help make our case. We have the following result:

Proposition 3: Return skewness is higher for less financially constrained firms.

Also, this relation should be stronger after 1982 than before. To test this proposition, we first define and construct daily skewness measures. We focus our analysis on daily return skewness since we know from existing work (see, e.g., Chen, Hong and Stein (1998)) that there is little skewness in returns at longer horizons because of the law of large numbers. Following Chen, Hong and Stein (2001), our measure of daily return skewness, which we denote DSKEW $_{i t}$, is calculated by taking the sample analog to the third 
moment of daily (raw) returns, and dividing it by the sample analog to the standard deviation of daily returns raised to the third power. These daily "returns" are, more precisely, actually log changes in price and dividend. We use log changes as opposed to simple daily percentage returns because they allow for a natural benchmark-if stock returns were lognormally distributed, then an DSKEW measure based on log changes should have a mean of zero. Scaling the raw third moment by the standard deviation cubed allows for comparisons across stocks with different variances; this is the usual normalization for skewness statistics. ${ }^{23}$

We next look at whether financially constrained firms also have less positively skewed returns (Proposition 3). To this end, we will implement the following crosssectional regression specification from Chen, Hong and Stein (2001):

DSKEW $_{\mathrm{it}}=\mathrm{b}_{0 \mathrm{t}}+\mathrm{b}_{1 \mathrm{t}}{ }^{*}$ CONSTRAINT $_{\mathrm{it}-1}+\mathrm{b}_{2 \mathrm{t}}{ }^{*}$ LOGSIZE $_{\mathrm{it}-1}+\mathrm{b}_{3 \mathrm{t}}$ MLEV $_{\mathrm{it}-1}+$ $\mathrm{b}_{4 \mathrm{t}}$ LOGMB $_{\mathrm{it}-1}+\mathrm{b}_{5 \mathrm{t}} * \mathrm{RET}_{\mathrm{it}-1}+\mathrm{b}_{6 \mathrm{t}} *$ TURNOVER $_{\mathrm{it}-1}+$ INDUSTRYDUMMIES $_{\mathrm{it}-1}+$ EXCHANGEDUMMIES $_{\text {it- } 1}+\varepsilon_{\text {it },} \quad \mathrm{i}=1, \ldots, \mathrm{N} \quad$ (10)

where CONSTRAINT is a proxy for the degree to which a firm is financing constrained. Here, $\varepsilon_{\text {it }}$ again stands for a generic error term that is uncorrelated with all other independent variables. The coefficient of interest is $b_{1 t}$, which captures the relation between financing constraints and return skewness controlling for a host of other firm characteristics (MLEV, LOGSIZE, LOGMB, RET, TURNOVER, INDUSTRYDUMMIES, and EXCHANGEDUMMIES). The specification in (10) is similar to that of Chen, Hong and Stein (2001) except for the financing constraint proxies. ${ }^{24}$ We then take the estimates from these annual regressions and follow Fama and MacBeth (1973) in taking their time series means and standard deviations to form our overall estimates of the effects of financing constraints on short-horizon return skewness.

The results are presented in Table 7. The dependent variable in Panel A is DSKEW, the skewness of daily returns. In column (1), the measure of financing

\footnotetext{
${ }^{23}$ See, e.g., Greene (1993).

${ }^{24}$ We have also tried adding lagged skewness as a control variable as in Chen, Hong and Stein and find that the results are unchanged. So we stay with the more parsimonious specification above. We have also included firm volatility controls and the results are similar to those reported here.
} 
constraint is REPO/VOLUME. The coefficient in front of REPO/VOLUME is of the right sign (0.0014) and statistically significant (with a t-statistic of 3.43). A two-standard deviation movement in REPO/VOLUME leads to an increase in firm return skewness that is about $7.4 \%$ of the standard deviation of DSKEW (which in our sample is 0.822 ).

Moreover, the coefficients on the control variables all come in with expected signs as found in Chen, Hong and Stein (2001): DSKEW becomes more negative with firm size, firm leverage, firm market-to-book LOGMB, past returns RET and stock turnover.

In column (2), we consider our second financing constraint proxy, firm age. The coefficient in front of AGE is positive and of the right sign and but is imprecisely measured. However, a two-standard deviation increase in firm age increases DSKEW by about $4.2 \%$ as a fraction of the standard deviation of DSKEW, which is comparable to the economic effect from REPO/VOLUME. In column (3), we look at the effect of KZ3 on DSKEW. The coefficient is of the right sign $(-0.0360)$ and statistically significant (with a t-statistic of 2.47). The economic effect is a sizeable implied movement in DSKEW of $7.3 \%$ as a fraction of the standard deviation of DSKEW. In sum, the evidence is in support of Proposition 3. All the coefficients are of the predicted sign and have interesting economic effects though one of our three measures is imprecisely measured. This is perhaps not too surprising given that skewness is notoriously difficult to measure.

In Panel B, we perform the same AFTER82 test now for skewness instead of volatility. The logic is the same: to the extent that repurchases were easier after 1982, we should expect our predicted relationships to be stronger after 1982 than before. This is indeed what we find. For all three financing constraint measures, the relationship between financing constraints and return skewness is much stronger after 1982. This difference is statistically significant for two of the three measures (REPO/VOLUME and KZ3). We think that Panel B strongly supports Proposition 3 and buttresses our firm intervention hypothesis.

\section{Conclusion}


Motivated by substantial evidence that firms are buyers-of-last resort for their own stocks, we develop a model to explore the effects of such firm intervention on stock returns. Our model generates two key predictions. Those with more ability to repurchase shares should prices drop far below fundamental value (less financially constrained ones) should have lower short-horizon return variance than other firms controlling for fundamental variance. Second, this relation is stronger in regimes in which it is legally easier to conduct repurchases. Using standard proxies for financing constraints such as firm payout ratios, firm age and the Kaplan-Zingales index, we find strong support for both of these predictions.

There is an analogy of firms being buyers of last resort for their own stocks to central banks being lenders of last resort for their economies. Moreover, we may be under-appreciating the macroeconomic significance of coordinated firm intervention as witnessed by the events of the Crash of 1987 and the events of September 11. As such, there can also be theoretical inquires into the role of such firm intervention along the lines of the vast literature on lenders of last resort. Much more work can be done on the topic of firms as buyers of last resort for their own stock and firm intervention in markets more generally. 


\section{References}

Almeida, Heitor, Murillo Campello and Michael Weisbach, 2004, The cash flow sensitivity of cash, Journal of Finance 59, 1777-1804.

Amihud, Yakov and Haim Mendelson, 1986, Asset pricing and the bid-ask spread, Journal of Financial Economics 17, 223-249.

Bagehot, Walter, 1873, Lombard Street: A Description of the Money Market, John Wiley and Sons, Inc., New Edition in 1999.

Baker, Malcolm, Richard S. Ruback and Jeffrey Wurgler, 2004, Behavioral corporate finance: A survey, forthcoming in the Handbook in Corporate Finance: Empirical Corporate Finance, edited by Espen Eckbo.

Baker, Malcolm, Jeremy Stein and Jeffrey Wurgler, 2003, When does the market matter? Stock prices and the investment of equity-dependent firms, Quarterly Journal of Economics 118, 969-1006.

Baker, Malcolm, and Jeffrey Wurgler, 2002, Market timing and capital structure, Journal of Finance 57, 1-32.

Bertrand Marianne, Esther Duflo and Sendhil Mullainathan, 2002, How much should we trust differences-in-differences estimates?, NBER working paper 8841.

Brav, Alon, John Graham, Campbell R. Harvey, and Roni Michaely, 2004, Payout policy in the 21 st century, Journal of Financial Economics, forthcoming.

Brennan, Michael J. and Avanidhar Subrahmanyam, 1996, Market microstructure and asset pricing: On the compensation for illiquidity in stock returns, Journal of Financial Economics 41, 441-64.

Campbell, John, Sanford J. Grossman, and Jiang Wang, 1993, Trading volume and serial correlation in stock returns, Quarterly Journal of Economics 108, 905-939.

Chen, Joseph, Harrison Hong and Jeremy C. Stein, 2001, Forecasting crashes; Trading volume, past returns and conditional skewness in stock prices, Journal of Financial Economics 61, 345-381.

Cohen, Randolph B., Christopher Polk, and Tuomo Vuolteenaho, 2006, The price is (almost) right, Harvard University Working Paper.

Coval, Joshua, and Erik Stafford, 2005, Asset fire sales (and purchases) in equity markets, Harvard Business School Working Paper, No. 05-077. Business.

Dittmar, Amy, 1999, Why do firms repurchase stock?, forthcoming in Journal of 
Fama, Eugene and Kenneth French, 1997, Industry costs of equity, Journal of Financial Economics 43, 153-193.

Fama, Eugene F., and James D. MacBeth, 1973, Risk, return and equilibrium: Empirical tests, Journal of Political Economy 81, 607-636.

Fazzari, S., R.G. Hubbard and B. Petersen, 1988, Financing constraints and corporate investment, Brookings Papers on Economic Activity 1, 141-195.

Frazzini, Andrea and Owen Lamont, 2005, Dumb money: Mutual fund flows and the cross-section of stock returns, Yale University Working Paper.

Gertler, M. and S. Gilchrist, 1994, Monetary policy, business cycles and the behavior of small manufacturing firms, Quarterly Journal of Economics 109, 309-340.

Greene, William H., 1993, Econometric Analysis, Prentice Hall.

Grossman, Sanford J. and Merton H. Miller, 1988, Liquidity and market structure, Journal of Finance 43, 617-633.

Grullon, Gustavo and Roni Michaely, 2002, Dividends, share repurchases and the substitution hypothesis, Journal of Finance 57, 1649-1684.

Hong, Harrison, Jeremy Stein and Jialin Yu, 2006, Simple Forecasts and Paradigm Shifts, Journal of Finance, forthcoming.

Huang, Jennifer and Jiang Wang, 2006, Market liquidity, asset prices and welfare, MIT Working Paper.

Ikenberry, David, Josef Lakonishok, and Theo Vermaelen, 1995, Market underreaction to open market share repurchases, Journal of Financial Economics 39, 181-208.

Ikenberry, David, Josef Lakonishok, and Theo Vermaelen, 2000, Stock repurchases in Canada: Performance and strategic trading, Journal of Finance 55, 23732398.

Kaplan, Steven N., and Luigi Zingales, 1997, Do investment-cash flow sensitivities provide useful measures of financing constraints?, Quarterly Journal of Economics 112, 169-215.

Kim, Jaemin and Ralf Schremper and Nikhil Varaiya, 2004, Survey on market repurchase regulations: Cross-country examination of the ten largest stock markets, San Diego State Working Paper. 
Lamont, Owen, Christopher Polk, and Jesus Saa-Requejo, 2001, Financial constraints and stock returns, Review of Financial Studies 14, 529-554.

Newey, Whitney and Kenneth West, 1987, A simple positive semi-definite, heteroskedasticity and autocorrelation consistent covariance matrix, Econometrica 55, 703-708.

Stein, Jeremy C., 1996, Rational capital budgeting in an irrational world, Journal of Business 69, 429-455.

Stephens, Clifford P. and Michael S. Weisbach, 1998, Actual share reacquisitions in open-market repurchase programs, Journal of Finance 53, 313-332.

Thompson, Samuel B., 2006, Simple formulas for standard errors that cluster by both firm and time, working paper. 


\section{Appendix}

\section{Solution to Equilibrium}

We first solve for the equilibrium at date 1 and 0 recursively. Let $\theta_{M}$ and $\theta_{F}$ denote the stock holding at date 1 . The optimization problem of a market maker is given by

The solution is

$$
\max _{\theta_{M}} \mathbf{E}_{\mathbf{1}}\left[-e^{-\theta_{M}\left(\widetilde{v}_{v}-\widetilde{P}_{1}\right) / \tau_{M}}\right]
$$

$$
\theta_{M}=\left(\tau_{M} / \sigma_{v}^{2}\right)\left(-\widetilde{p}_{1}\right)
$$

The optimization problem of the firm is given by

$$
\max _{\theta_{F} \geq 0} \quad \mathbf{E}_{\mathbf{1}}\left[-e^{-\theta_{F}\left(\widetilde{v}_{v}-\widetilde{p}_{1}\right) / \tau_{F}}\right]
$$

The solution is

$$
\theta_{F}= \begin{cases}\left(\tau_{F} / \sigma_{v}^{2}\right)\left(-\widetilde{p}_{1}-\kappa\right), & \tilde{p}_{1}<-\kappa \\ 0, & \text { otherwise }\end{cases}
$$

The market clearing condition requires that

which leads to the equilibrium price:

$$
\mu \theta_{M}+\theta_{F}=\tilde{x}
$$

$$
\tilde{p}_{1}= \begin{cases}-\kappa-\frac{\sigma_{v}^{2}}{\tau_{M}+\tau_{F}}\left(\tilde{x}-x^{*}\right), & \tilde{x} \geq x^{*} \\ -\frac{\sigma_{v}^{2}}{\tau_{M}} \widetilde{x}, & \tilde{x}<x^{*}\end{cases}
$$

where $x^{*}=\left(\tau_{M} / \sigma_{v}^{2}\right) \kappa$. In the limit of $\tau_{F} \rightarrow \infty$, we have

$$
\widetilde{p}_{1}=\left\{\begin{array}{ll}
-\frac{\sigma_{v}^{2}}{\tau_{M}} x^{*}, & \tilde{x} \geq x^{*} \\
-\frac{\sigma_{v}^{2}}{\tau_{M}} \tilde{x}, & \tilde{x}<x^{*}
\end{array}=-\left(\sigma_{v}^{2} / \tau_{M}\right) \min \left(\tilde{x}, x^{*}\right) .\right.
$$

Now let us consider the equilibrium at date 0 . Only market makers are present then. Let $\theta_{M 0}$ denote a market maker's stock holding at date 0 . His optimization problem is

$$
\max _{\theta_{M 0}} \quad \mathbf{E}_{\bullet}\left[-e^{-\theta_{M 0}\left(\widetilde{p}_{1}-p_{0}\right) / \tau_{M}-\frac{1}{2 \sigma_{v}^{2}}\left(-\widetilde{p}_{1}\right)^{2}}\right]
$$

Since $\theta_{M 0}=0$ in equilibrium, from the optimality condition for $\theta_{M 0}$ we obtain Equation (3) for the equilibrium stock price at 0.

\section{Proof of Proposition 1}

Without loss of generality, we set $\sigma_{x}=1$. Let $m_{k}$ denote the $k$-th moment of $\tilde{p}_{1}$ :

$$
m_{k} \equiv \mathbf{E}\left[\tilde{p}_{1}^{k}\right]=(-1)^{k}\left(\sigma_{v}^{2} / \tau_{M}\right)^{k} \mathbf{E}\left[\left\{\min \left(\tilde{x}, x^{*}\right)\right\}^{k}\right] .
$$

Give that $\tilde{x}$ is a standard normal, we have 


$$
\begin{aligned}
& m_{1}=\frac{1}{\sqrt{2 \pi}} e^{-\frac{1}{2} x^{* 2}}-x^{*}\left[1-N\left(x^{*}\right)\right] \\
& m_{2}=\int_{-\infty}^{x^{*}} x^{2} n(x) d x+\int_{x^{*}}^{\infty} x^{* 2} n(x) d x
\end{aligned}
$$

and

$$
\frac{d m_{1}}{d x^{*}}=-\left[1-N\left(x^{*}\right)\right], \quad \frac{d m_{2}}{d x^{*}}=2 x^{*}\left[1-N\left(x^{*}\right)\right], \quad \frac{d x^{*}}{d \kappa}=\sigma_{v}^{2} / \tau_{M} .
$$

The variance of return $\widetilde{r}_{1}$ is given by

$$
\sigma^{2}(1) \equiv \operatorname{Var}\left[\widetilde{r}_{1}\right]=\operatorname{Var}\left[v_{1}+\widetilde{p}_{1}\right]=\sigma_{v}^{2}+\left(\sigma_{v}^{2} / \tau_{M}\right)\left(m_{2}-m_{1}^{2}\right) .
$$

We have

$$
\frac{d \sigma^{2}(1)}{d \kappa}=2\left(\sigma_{v}^{2} / \tau_{M}\right)^{2}\left[1-N\left(x^{*}\right)\right]\left(x^{*}+m_{1}\right) \geq 0 .
$$

Since $\sigma^{2}(2)=2 \sigma_{v}^{2}$, Proposition 1 follows.

\section{Proof of Proposition 3}

Let $s$ denote the skewness of the stock return. The skewness of return $\widetilde{r}_{1}=\widetilde{v}_{1}+\widetilde{p}_{1}-p_{0}$ is

$$
s \equiv \mathbf{E}\left[\left(\widetilde{r}_{1}-\mathbf{E}\left[\widetilde{r}_{1}\right]\right)^{3}\right]=\mathbf{E}\left[\left(\widetilde{p}_{1}-\mathbf{E}\left[\widetilde{p}_{1}\right]\right)^{3}\right]=m_{3}-3 m_{2} m_{1}+2 m_{1}^{3} .
$$

Then, it is easy to show that

$$
\frac{d s}{d \kappa}=-3[1-N(\kappa)]\left[\left(\kappa+m_{1}\right)^{2}-\left(m_{2}-m_{1}^{2}\right)\right] .
$$

For $\kappa=\infty, m_{3}=0$ and $d s / d k<0$. Thus, for $\kappa$ sufficiently large, $s$ is positive and decreases with $\kappa$ as stated in Proposition 3. 


\section{Randomized inference for US.}

We want to test the null hypothesis that the AFTER 82 effect $c_{1}$ is 0 in

$$
\hat{\beta}_{t}=c_{0}+c_{1} \times \text { AFTER82 } 2_{t}+\eta_{t}
$$

The dummy AFTER82 ${ }_{t}$ ( 1 if the year of the cross-sectional regression is after 1982 and 0 otherwise) is assumed to be independent of $\eta_{t} . \hat{\beta}_{t}$ is the coefficient in front of constraint in the cross-sectional regression of year $t$,

$$
S T V A R_{t}=X_{t} \cdot \beta_{t}+\varepsilon_{t}
$$

STVAR is a vector of return variances for various stocks, $X$ is a matrix of regressors. The Newey-West (1987) t-statistics in the Panel A of Table 4 allows for auto-correlations of finite lags for $\eta$. The persistence in volatility can imply $\eta$ is auto-correlated at all lags. This can arise for example if

$$
\varepsilon_{t}=\phi+\omega_{t}
$$

The vector $\phi$ captures a persistent shock to the return variances of different stocks. $\omega_{t}$ is assumed to be i.i.d. across time. In this case, letting $M_{t}=\left(X_{t}^{\prime} X_{t}\right)^{-1} X_{t}^{\prime}$, the linear regression coefficient

$$
\begin{aligned}
& \hat{\beta}_{t}=\beta_{t}+M_{t}\left(\phi+\omega_{t}\right)
\end{aligned}
$$

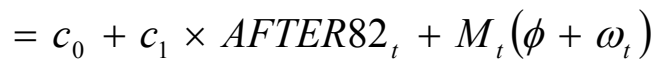

This creates persistence at all lags. Such persistence, together with the cross-sectional correlation of volatility, is difficult to deal with using typical methods of inference. We use a randomized inference procedure to calculate an alternative t-statistic robust to such persistence. To begin, notice that under the null of $c_{1}=0, \hat{\beta}_{t}=c_{0}+M_{t}\left(\phi+\omega_{t}\right)$ has the same marginal distribution across year $t$ as long as $M_{t}$ is stationary. Further, letting $\underline{t}$ and $\bar{t}$ denote the first and last years in the sample, the joint distribution of $\left(\hat{\beta}_{t}, \hat{\beta}_{t+1}, \ldots, \hat{\beta}_{\bar{t}}\right)$ remains the same if the time indices are reshuffled as long as the joint distribution of $\left(M_{t}, M_{t+1}, \ldots, M_{\bar{t}}\right)$ remains the same after reshuffling of the years. This includes but is not restricted to the case where $M$ is i.i.d. or highly persistent (e.g., $M_{t}=m+\xi_{t}$ where $\xi_{t}$ is i.i.d. across time). As a result, if we reshuffle the time index $t$, the resulting estimator of $c_{1}$ will have the same distribution as the estimator using the unshuffled data under the null, as long as the number of years with AFTER82 being 0 or 1 equal that in the un-shuffled data. If we conduct a simulation by randomly shuffling years, the resulting estimator $c_{1}$ using shuffled data will trace out the distribution of the estimator using the un-shuffled data. We will use the standard deviation of the $c_{1}$ estimates using shuffled data to calculate an alternative t-statistic valid in small samples that is robust to severe auto-correlation of stock return variances

$$
\hat{t}=\frac{\hat{c}_{1}(\text { unshuffled data })}{\text { Std. Dev. }\left(\hat{c}_{1}(\text { shuffled data })\right)}
$$


Such randomized inference is robust to other types of auto-correlations. For example,

$$
\varepsilon_{t}=\sigma_{t} \phi+\omega_{t}
$$

where the i.i.d. variable $\sigma_{t}$ captures the time variation of the sensitivity of $\varepsilon_{t}$ to the persistent variable $\phi$. This can arise if the market incorporates information in $\phi$ differently at different points in time as in Hong, Stein and $\mathrm{Yu}$ (2006). One can easily verify that the previous analysis holds under this setup. Similarly, the randomized inference allows the regressor to have time-varying sensitivity to its persistent component, e.g. $M_{t}=\sigma_{t} m+\xi_{t}$. The randomized inference also holds in the special case when $\phi=0$ (no persistence) which reduces to the randomized inference method in Bertrand, Duflo and Mullainathan (2002).

To generate re-shuffled years in the simulation, we generate a continuous random variable $\pi_{t}$ (any continuous distribution will do and we choose uniform distribution) for each year and sort years into ascending orders of $\pi_{t}$. We then pick a cut-off value so that years with $\pi_{t}$ less than the cut-off value are assigned $A F T E R 82_{t}=0$ and the rest of years are assigned $A F T E R 82_{t}=1$. The cut-off value is chosen so that the number of years with $A F T E R 82_{t}=1$ is the same as that in the actual estimation. 1000 reshuffles are repeated and we use the standard deviation of the 1000 estimates from the reshuffled data as an alternative measure of the standard error for the actual estimate.

\section{Randomized inference - International evidence}

We conduct a simulation of 1000 iterations. In each iteration, we randomly reshuffle the 10 countries into the EASY, MEDIUM, and DIFFICULT groups such that the number of countries in each group coincides with that in the actual estimation ( 3 countries in EASY group, 5 countries in MEDIUM group and 2 countries in DIFFICULT group). Specifically, we generate a continuous random variable $\pi_{t}$ (any continuous distribution will do and we chose uniform distribution) for each country and sort countries into ascending orders of $\pi_{t}$. The first 3 countries are classified as EASY, the next 5 countries are classified as MEDIUM, and the last 2 countries are classified as DIFFICULT. We then run the pooled international regression using the randomly assigned ease-ofrepurchase groups. We calculate the fraction of simulation outcomes in which $c_{1}-c_{2}$ and $c_{2}-c_{3}$ exceed those in the actual estimation. 


\section{Table 1: Summary Statistics}

This table reports various time-series averages of cross-sectional means and standard deviations. Return variances at various horizons include DVAR (daily), WVAR (weekly), MVAR (monthly), QVAR (quarterly) and TVAR (three-year). CVAR is the cash-flow variance. REPO/VOLUME is firm repurchases to daily dollar trading volume. REPO/MKT is firm repurchases to market capitalization. AGE is the number of years a stock has price data in CRSP monthly file which starts in 1925 . KZ is the Kaplan-Zingales index of financing constraints and KZ3 is the KZ index net of book leverage and firm market-to-book ratio. LOGSIZE is log market capitalization. TURNOVER is monthly turnover. RET is average monthly return in a year. LOGMB is log market-to-book ratio. MLEV is market leverage. US data are from 1971-2005 for REPO/VOLUME and REPO/MKT and from 1963-2005 for other variables. All other countries are from 1993-2003.

\begin{tabular}{|c|c|c|c|c|c|c|c|c|c|c|}
\hline & US & & UK & & Canada & & Germany & & France & \\
\hline & Mean & Std Dev & Mean & Std Dev & Mean & Std Dev & Mean & Std Dev & Mean & Std Dev \\
\hline \multicolumn{11}{|c|}{ Annualized return variance } \\
\hline DVAR & 0.2333 & 0.2427 & & & & & & & & \\
\hline WVAR & 0.1936 & 0.1523 & & & & & & & & \\
\hline MVAR & 0.1768 & 0.1376 & 0.1889 & 0.1993 & 0.2873 & 0.3139 & 0.1432 & 0.1336 & 0.1700 & 0.1978 \\
\hline QVAR & 0.1840 & 0.1566 & 0.2059 & 0.2414 & 0.2935 & 0.3470 & 0.1595 & 0.1561 & 0.1832 & 0.2109 \\
\hline TVAR & 0.1826 & 0.3420 & 0.2803 & 0.5823 & 0.3758 & 0.7808 & 0.1565 & 0.3153 & 0.1985 & 0.3982 \\
\hline CVAR & 0.0763 & 0.3199 & 0.2443 & 0.7891 & 0.2357 & 0.5767 & 0.2612 & 1.1174 & 0.1198 & 0.5581 \\
\hline \multicolumn{11}{|c|}{ Financing constraint measure } \\
\hline REPO/VOLUME & 7.219 & 21.578 & & & & & & & & \\
\hline REPO/MKT & 0.0125 & 0.0322 & & & & & & & & \\
\hline AGE & 17.80 & 15.56 & & & & & & & & \\
\hline KZ3 & -1.1054 & 0.8377 & -1.5666 & 1.2786 & -0.7189 & 1.0631 & -0.8394 & 1.0543 & -0.3555 & 0.3653 \\
\hline $\mathrm{KZ}$ & 0.3964 & 1.1726 & -0.0095 & 1.5955 & 0.9879 & 1.5083 & 0.8127 & 1.5797 & 1.3536 & 0.8895 \\
\hline \multicolumn{11}{|l|}{ Other } \\
\hline LOGSIZE & 11.9807 & 1.6981 & 4.2241 & 2.3020 & 5.3735 & 1.7013 & 5.7055 & 1.8806 & 6.9385 & 2.0195 \\
\hline TURNOVER & 0.0535 & 0.0504 & 0.0480 & 0.0572 & 0.0408 & 0.0430 & 0.0378 & 0.0884 & 0.0296 & 0.0502 \\
\hline RET & 0.0152 & 0.0365 & 0.0086 & 0.0391 & 0.0177 & 0.0531 & 0.0028 & 0.0470 & 0.0107 & 0.0423 \\
\hline LOGMB & 0.3683 & 0.6823 & 0.3200 & 1.7660 & 0.4078 & 1.0652 & 0.5551 & 0.9845 & 0.4372 & 1.0979 \\
\hline MLEV & 0.2767 & 0.2119 & 0.2456 & 0.2575 & 0.2831 & 0.2728 & 0.2939 & 0.2675 & 0.3232 & 0.2512 \\
\hline
\end{tabular}




\begin{tabular}{|c|c|c|c|c|c|c|c|c|c|c|}
\hline & Japan & & Italy & & Switzerland & & Netherland & & HongKong & \\
\hline & Mean & Std Dev & Mean & Std Dev & Mean & Std Dev & Mean & Std Dev & Mean & Std Dev \\
\hline \multicolumn{11}{|c|}{ Annualized return variance } \\
\hline \multicolumn{11}{|c|}{ DVAR } \\
\hline \multicolumn{11}{|l|}{ WVAR } \\
\hline MVAR & 0.1923 & 0.1520 & 0.1728 & 0.0905 & 0.1372 & 0.1550 & 0.1448 & 0.1643 & 0.3790 & 0.3449 \\
\hline QVAR & 0.2108 & 0.1813 & 0.2040 & 0.1036 & 0.1696 & 0.2011 & 0.1714 & 0.2119 & 0.3976 & 0.4252 \\
\hline TVAR & 0.1801 & 0.3124 & 0.2368 & 0.3354 & 0.2311 & 0.5145 & 0.1745 & 0.3215 & 0.2862 & 0.4668 \\
\hline CVAR & 0.0698 & 0.3364 & 0.0867 & 0.2348 & 0.1819 & 0.6454 & 0.1313 & 0.3391 & 0.1647 & 0.5985 \\
\hline \multicolumn{11}{|c|}{ Financing constraint measure } \\
\hline \multicolumn{11}{|c|}{ REPO/VOLUME } \\
\hline \multicolumn{11}{|l|}{ REPO/MKT } \\
\hline \multicolumn{11}{|l|}{ AGE } \\
\hline KZ3 & -0.4745 & 0.2789 & -0.5299 & 0.6999 & -1.6194 & 6.8418 & -1.1941 & 1.0023 & -1.6119 & 2.8976 \\
\hline $\mathrm{KZ}$ & 1.2651 & 1.0389 & 1.2314 & 1.1827 & 0.4100 & 5.7943 & 0.4712 & 1.3817 & -0.3478 & 3.2866 \\
\hline \multicolumn{11}{|l|}{ Other } \\
\hline LOGSIZE & 9.9378 & 1.5475 & 12.5805 & 2.1072 & 5.7134 & 1.8047 & 6.0141 & 2.0578 & 7.3497 & 1.8528 \\
\hline TURNOVER & 0.0280 & 0.0421 & 0.0548 & 0.0883 & 0.0594 & 0.1079 & 0.0842 & 0.0873 & 0.0558 & 0.0905 \\
\hline RET & -0.0017 & 0.0325 & 0.0109 & 0.0360 & 0.0105 & 0.0357 & 0.0089 & 0.0346 & 0.0097 & 0.0479 \\
\hline LOGMB & 0.2236 & 0.6672 & -0.5661 & 1.6905 & 0.0966 & 1.0303 & 0.5481 & 1.3393 & -0.1711 & 0.9141 \\
\hline MLEV & 0.3676 & 0.2533 & 0.5030 & 0.3220 & 0.3952 & 0.2544 & 0.2685 & 0.2447 & 0.3053 & 0.2483 \\
\hline
\end{tabular}


Table 2: Correlatedness of Financing Constraint Proxies, U.S. Stock Market

This table reports the results of the correlation of the various financing constraint proxies. Panel A reports the timeseries average of the cross-sectional correlation matrix for the five financing constraint proxies, along with the NeweyWest (1987) t-statistics in the parentheses. Panel B reports the results of Fama-MacBeth regressions of REPINITIATE (a dummy variable that equals 1 if a firm initiated a repurchase program in a given year and zero otherwise) on previous year values of REPO/VOLUME, AGE and KZ3. Panel C reports the results of Fama-MacBeth regression of REPO/VOLUME on previous year values of REPO/VOLUME, AGE and KZ3. The regressions in panels B-C include Fama-French (1997) industry dummies. Newey-West (1987) t-statistics are in the parentheses.

Panel A: Correlation matrix

\begin{tabular}{c|ccccc}
\hline & REPO/VOLUME & REPO/MKT & AGE & KZ3 & KZ \\
\hline REPO/VOLUME & 1 & & & & \\
\hline REPO/MKT & $0.772(95.74)$ & 1 & & & \\
\hline AGE & $0.045(1.96)$ & $0.136(9.63)$ & 1 & 1 & \\
\hline KZ3 & $-0.018(1.10)$ & $-0.005(0.36)$ & $-0.219(11.11)$ & 1 \\
\hline KZ & $-0.061(3.45)$ & $-0.037(1.95)$ & $-0.185(13.62)$ & $0.785(14.77)$ & \\
\hline
\end{tabular}

Panel B: Dependent Variable is indicator of share repurchase authorization (REPINITIATE)

\begin{tabular}{ccccc}
\hline & $\begin{array}{c}\text { REPINITIATE }_{\mathrm{t}} \\
(1)\end{array}$ & $\begin{array}{c}\text { REPINITIATE }_{\mathrm{t}} \\
(2)\end{array}$ & $\begin{array}{c}\text { REPINITIATE }_{\mathrm{t}} \\
(3)\end{array}$ & $\begin{array}{c}\text { REPINITIATE }_{\mathrm{t}} \\
(4)\end{array}$ \\
\hline $\begin{array}{c}\text { REPO/VOLUME } \\
\mathrm{t}-1\end{array}$ & 0.0035 & & & 0.0032 \\
\hline $\mathrm{AGE}$ & $(7.27)$ & & & $(6.91)$ \\
\hline $\mathrm{KZ3}$ & & 0.0022 & 0.0014 \\
\hline & $(10.65)$ & & $(8.16)$ \\
\hline Constant & & & -0.0394 & -0.0338 \\
\hline & 0.0783 & 0.0609 & $(30.29)$ & $(18.11)$ \\
\hline & $(4.06)$ & $(3.61)$ & 0.0680 & 0.0473 \\
\hline
\end{tabular}

Panel C: Dependent Variable is firm repurchases to daily dollar trading volume (REPO/VOLUME)

\begin{tabular}{ccccc}
\hline & $\begin{array}{c}\text { REPO/VOLUME } \\
\text { t }\end{array}$ & $\begin{array}{c}\text { REPO/VOLUME }_{\mathrm{t}} \\
(1)\end{array}$ & $\begin{array}{c}\text { REPO/VOLUME }_{\mathrm{t}} \\
(3)\end{array}$ & $\begin{array}{c}\text { REPO/VOLUME }_{\mathrm{t}} \\
(4)\end{array}$ \\
\hline REPO/VOLUME $_{\mathrm{t}-1}$ & 0.3882 & & & 0.3872 \\
\hline & $(26.17)$ & & & $(25.23)$ \\
\hline AGE & & 0.0388 & 0.0052 \\
\hline KZ3 & $(1.66)$ & -0.3179 & $(0.33)$ \\
\hline Constant & & & $(0.69)$ & -0.0731 \\
\hline & 7.0526 & 9.4150 & 9.6083 & $(0.24)$ \\
\hline & $(2.68)$ & $(2.48)$ & $(2.47)$ & 6.6932 \\
\hline
\end{tabular}


Table 3: Stock Return Variance and Financing Constraint, U.S. Stock Market

This table reports the Fama-MacBeth regression results of return variances at various horizons on financing constraint measures. Return variances at various horizons include DVAR (daily), WVAR (weekly), MVAR (monthly) and QVAR (quarterly). CONSTRAINT is given by the following three financing constraint proxies. REPO/VOLUME is firm repurchases to daily dollar trading volume. AGE is the number of years a stock has price data in CRSP monthly file which starts in 1925. KZ3 is the Kaplan-Zingales index of financing constraints net of book leverage and firm market-to-book ratio. CVAR is cash-flow variance. LOGSIZE is log market capitalization. MLEV is market leverage. LOGMB is log market-to-book ratio. RET is average monthly return in a year. TURNOVER is monthly turnover. The regressions include Fama-French (1997) industry dummies and exchange dummies for NASDAQ and AMEX. The sample period is 1971-2005 for REPO/VOLUME and 1963-2005 for AGE and KZ3. Newey-West (1987) t-statistics are in the parentheses.

Panel A: Dependent variable is daily return variance (DVAR)

\begin{tabular}{cccc}
\hline & $\begin{array}{c}\text { REPO/VOLUME } \\
(1)\end{array}$ & $\begin{array}{c}\text { AGE } \\
(2)\end{array}$ & $\begin{array}{c}\text { KZ3 } \\
(3)\end{array}$ \\
\hline CONSTRAINT & -0.0007 & -0.0002 & 0.0342 \\
\hline & $(2.11)$ & $(2.38)$ & $(7.91)$ \\
\hline CVAR & 0.1640 & 0.1382 & 0.1407 \\
\hline & $(12.38)$ & $(9.98)$ & $(9.02)$ \\
\hline LOGSIZE & -0.0493 & -0.0425 & -0.0400 \\
\hline MLEV & $(4.01)$ & $(3.37)$ & $(3.52)$ \\
\hline & 0.0626 & 0.0582 & 0.0119 \\
\hline LOGMB & $(2.77)$ & $(3.22)$ & $(0.65)$ \\
\hline & 0.0152 & 0.0200 & 0.0242 \\
\hline RET & $(2.31)$ & $(3.27)$ & $(3.65)$ \\
\hline TURNOVER & -0.7305 & -0.7243 & -0.7254 \\
\hline & $(5.42)$ & $(5.67)$ & $(6.49)$ \\
\hline & 0.6184 & 0.7431 & 0.6160 \\
\hline & $(2.75)$ & $(3.16)$ & $(3.13)$ \\
\hline
\end{tabular}

Panel B: Coefficient in front of CONSTRAINT from regressions in which the dependent variables are weekly return variance (WVAR), monthly return variance (MVAR), and quarterly return variance (QVAR)

\begin{tabular}{cccc}
\hline & REPO/VOLUME & AGE & KZ3 \\
& $(1)$ & $(2)$ & $(3)$ \\
\hline WVAR & -0.0005 & -0.0005 & 0.0277 \\
\hline & $(2.18)$ & $(2.72)$ & $(9.68)$ \\
\hline MVAR & -0.0005 & -0.0006 & 0.0255 \\
\hline QVAR & $(2.13)$ & $(2.62)$ & $(8.58)$ \\
\hline & -0.0005 & -0.0007 & 0.0272 \\
\hline & $(2.20)$ & $(3.33)$ & $(11.78)$ \\
\hline
\end{tabular}


Table 4: The Relation between Return Variances and Financing Constraints in the U.S. Stock Market, Before and After the Regulatory Reforms of 1982

Panel A of this table reports the results of a time-series regression using the coefficients in front of CONSTRAINT from the annual cross-sectional regressions in Table 3. These coefficients are regressed on a constant and a dummy variable AFTER82 that equals one if the year of the cross-sectional regression is after 1982 and zero otherwise. Newey-West (1987) t-statistics with twelve lags are in parentheses. In Panel B, the AFTER82 dummy is first randomly assigned to be 0 or 1 so that the total number of years with AFTER82=1 equals that in panel $\mathrm{A}$ and then run the regression specification in panel A. This reshuffle of the AFTER82 dummy is repeated 1000 times. Panel B reports the average of the regression coefficient in front of AFTER82 and the average of its Newey-West t-statistics across the 1000 reshuffles. Also reported in panel B is an alternative t-statistics of the AFTER82 estimate in panel A using the standard deviation of the 1000 estimates in the regressions of reshuffled data to measure the standard error.

Panel A. US stock market before and after the regulatory reforms of 1982

\begin{tabular}{cccc}
\hline & $\begin{array}{c}\text { REPO/VOLUME } \\
(1)\end{array}$ & $\begin{array}{c}\text { AGE } \\
(2)\end{array}$ & $\begin{array}{c}\text { KZ3 } \\
(3)\end{array}$ \\
\hline DVAR & & -0.0001 & 0.0259 \\
\hline Constant & -0.0001 & $(1.01)$ & $(6.60)$ \\
\hline & $(5.36)$ & -0.0003 & 0.0170 \\
\hline AFTER82 & -0.0009 & $(1.99)$ & $(3.82)$ \\
\hline WVAR & $(2.71)$ & & \\
\hline Constant & -0.0001 & -0.0002 & 0.0224 \\
\hline \multicolumn{5}{c}{$(11.58)$} & $(3.10)$ & $(7.31)$ \\
\hline AFTER82 & -0.0007 & -0.0006 & 0.0108 \\
\hline MVAR & $(2.39)$ & $(2.82)$ & $(3.42)$ \\
\hline Constant & -0.0001 & -0.0002 & 0.0200 \\
\hline \multicolumn{5}{c}{} & $(8.61)$ & -0.0007 & $(7.32)$ \\
\hline AFTER82 & -0.0006 & $(2.59)$ & 0.0113 \\
\hline QVAR & $(2.31)$ & $3.31)$ \\
\hline Constant & -0.0001 & -0.0004 & 0.0232 \\
\hline & $(6.03)$ & $(7.00)$ & $(6.91)$ \\
\hline AFTER82 & -0.0006 & -0.0007 & 0.0082 \\
\hline & $(2.44)$ & $(2.58)$ & $(2.21)$ \\
\hline
\end{tabular}

Panel B. Randomized Inference

\begin{tabular}{|c|c|c|c|}
\hline & $\begin{array}{c}\text { REPO/VOLUME } \\
(1)\end{array}$ & $\begin{array}{l}\text { AGE } \\
(2)\end{array}$ & $\begin{array}{c}\text { KZ3 } \\
(3)\end{array}$ \\
\hline \multicolumn{4}{|l|}{ DVAR } \\
\hline Average AFTER82 & $2.70 \mathrm{E}-06$ & 4.19E-07 & 0.0001 \\
\hline Average t(AFTER82) & -0.05 & 0.01 & 0.08 \\
\hline AFTER82 in Panel A / Std Dev(AFTER82) & $(2.85)$ & $(2.19)$ & $(3.91)$ \\
\hline \multicolumn{4}{|l|}{ WVAR } \\
\hline Average AFTER82 & $1.78 \mathrm{E}-06$ & $1.01 \mathrm{E}-06$ & $4.18 \mathrm{E}-05$ \\
\hline Average t(AFTER82) & -0.06 & 0.00 & 0.08 \\
\hline AFTER82 in Panel A / Std Dev(AFTER82) & $(2.71)$ & $(3.92)$ & $(3.84)$ \\
\hline \multicolumn{4}{|l|}{ MVAR } \\
\hline Average AFTER82 & $1.89 \mathrm{E}-06$ & $1.42 \mathrm{E}-06$ & $2.13 \mathrm{E}-05$ \\
\hline Average t(AFTER82) & -0.05 & 0.00 & 0.06 \\
\hline AFTER82 in Panel A / Std Dev(AFTER82) & $(2.76)$ & $(3.78)$ & $(3.79)$ \\
\hline \multicolumn{4}{|l|}{ QVAR } \\
\hline Average AFTER82 & $8.34 \mathrm{E}-07$ & $1.20 \mathrm{E}-06$ & $4.38 \mathrm{E}-06$ \\
\hline Average t(AFTER82) & -0.06 & 0.00 & 0.04 \\
\hline AFTER82 in Panel A / Std Dev(AFTER82) & $(2.82)$ & $(3.52)$ & $(2.33)$ \\
\hline
\end{tabular}


Table 5: Relation Between Return Variances and Financing Constraints, International Evidence

This table reports the results of pooled regressions of return variances on financing constraint measures KZ3 and KZ using all stock markets during the period of 1993-1998. These regressions are analogous to those in Table 3 and Table 4 except that the regressions are pooled and we allow the effect of each of the control variables (LOGSIZE, TURNOVER, RET, LOGMB, MLEV) to vary by country (US, Canada, UK, Germany, France, Japan, Italy, Switzerland, Netherlands, Hong Kong) and the effect of the financing constraint variables (KZ3 and KZ) to vary by ease-of-repurchase country groups (EASY which includes US, Canada and UK, DIFFICULT which includes Germany and France, and MEDIUM which includes the remaining countries). The regressions include country and year dummies. We only report the coefficients in front of EASY x CONSTRAINT, MEDIUM x CONSTRAINT and DIFFICULT x CONSTRAINT. Panel A reports the results for KZ3 and B reports the results for KZ. Newey-West (1987) t-statistics are reported in the parentheses. Panel C reports the upper bound of the p-value of the joint test that the coefficient in front of EASY $\mathrm{x}$ CONSTRAINT is greater than the coefficient in front of MEDIUM $\mathrm{x}$ CONSTRAINT is greater than the coefficient in front of DIFFICULT $x$ CONSTRAINT. Panel D first randomly reshuffles each country into the EASY, MEDIUM and DIFFICULT groups so that the total number of countries in each group equals that in panel A and B and then run the regression specification in panel A and B on the reshuffled data. 1000 reshuffles are repeated. Panel D reports the average coefficients and average Newey-West t-statistics of EASY x CONSTRAINT, MEDIUM $x$ CONSTRAINT and DIFFICULT $x$ CONSTRAINT in the regressions using the reshuffled data. Also reported is the fraction of reshuffles such that the differences in the coefficients of constraint between EASY and MEDIUM group and between MEDIUM and DIFFICULT group are larger than those in Panels A and $\mathrm{B}$.

Panel A: Results for KZ3

\begin{tabular}{lcc}
\hline & MVAR & QVAR \\
& $(1)$ & $(2)$ \\
\hline EASY x KZ3 & 0.0302 & 0.0323 \\
\hline & $(7.30)$ & $(6.82)$ \\
\hline MEDIUM x KZ3 & 0.0045 & 0.0035 \\
\hline DIFFICULT x KZ3 & $(1.57)$ & $(1.07)$ \\
\hline & -0.0361 & -0.0434 \\
\hline
\end{tabular}

Panel B: Results for KZ

\begin{tabular}{lcc}
\hline & $\begin{array}{c}\text { MVAR } \\
(1)\end{array}$ & $\begin{array}{c}\text { QVAR } \\
(2)\end{array}$ \\
\hline EASY x KZ & 0.0329 & 0.0356 \\
\hline & $(8.31)$ & $(7.91)$ \\
\hline MEDIUM x KZ & 0.0044 & 0.0037 \\
\hline DIFFICULT x KZ & $(1.61)$ & $(1.11)$ \\
\hline & -0.0296 & -0.0367 \\
\hline
\end{tabular}

Panel C: Upper bound of the p-value of the joint test that the financing constraint effect is stronger in easier to repurchase countries

\begin{tabular}{lcc}
\hline & $\begin{array}{c}\text { MVAR } \\
(1)\end{array}$ & $\begin{array}{c}\text { QVAR } \\
(2)\end{array}$ \\
\hline KZ3 & 0.022 & 0.018 \\
\hline KZ & 0.029 & 0.022 \\
\hline
\end{tabular}


Panel D. Randomized Inference

\begin{tabular}{ccc}
\hline & $\begin{array}{c}\text { MVAR } \\
(1)\end{array}$ & $\begin{array}{c}\text { QVAR } \\
(2)\end{array}$ \\
\hline KZ3 & & \\
\hline Average coef (EASY x KZ3) & 0.0122 & 0.0138 \\
\hline Average coef (MEDIUM x KZ3) & 0.0161 & 0.0170 \\
\hline Average coef (DIFFICULT x KZ3) & 0.0078 & 0.0102 \\
\hline Average t (EASY x KZ3) & 3.78 & 3.38 \\
\hline Average t (MEDIUM x KZ3) & 5.69 & 5.01 \\
\hline Average t (DIFFICULT x KZ3) & 2.74 & 2.48 \\
\hline Fraction EASY-MED $>$ Panel A \& MED-DIFF $>$ Panel A & 0.025 & 0.022 \\
\hline KZ & & \\
\hline Average coef (EASY x KZ) & 0.0151 & 0.0168 \\
\hline Average coef (MEDIUM x KZ) & 0.0184 & 0.0196 \\
\hline Average coef (DIFFICULT x KZ) & 0.0111 & 0.0136 \\
\hline Average t (EASY x KZ) & 4.60 & 4.16 \\
\hline Average t (MEDIUM x KZ) & 6.79 & 6.09 \\
\hline Average t (DIFFICULT x KZ) & 3.39 & 3.09 \\
\hline Fraction EASY-MED $>$ Panel A \& MED-DIFF $>$ Panel A & 0.021 & 0.008 \\
\hline
\end{tabular}




\section{Table 6: Robustness Checks}

This table reports various robustness check results. Panel A reports the pooled regression analog to the results in Table 3 with the exception of including year dummies in the regression. The sample period is 1971-2005 for REPO/VOLUME, is 1963-2005 for AGE and KZ3. The coefficients in front of CONSTRAINT in these pooled regressions are reported in Panel A. The t-statistics in the parentheses are adjusted for heteroskedasticity and correlation using Thompson (2006). Panel B and Panel E repeat the regressions in Table 3 and Table 5 using the log instead of the level of the cash-flow variance CVAR and stock return variances. Panel $\mathrm{C}$ and panel $\mathrm{F}$ repeat the regressions in Table 3 and Table 5, except that the cash flow variance is replaced by three-year stock return variance. Panel D repeats the regression in Panel A of Table 4 using REPO/MKT and KZ as proxies of constraint.

Panel A. Coefficient in front of CONSTRAINT in pooled regressions of stock return variance on financing constraint

\begin{tabular}{cccc}
\hline & $\begin{array}{c}\text { REPO/VOLUME } \\
(1)\end{array}$ & $\begin{array}{c}\text { AGE } \\
(2)\end{array}$ & $\begin{array}{c}\text { KZ3 } \\
(3)\end{array}$ \\
\hline DVAR & -0.0005 & -0.0002 & 0.0385 \\
\hline & $(3.95)$ & $(0.94)$ & $(11.26)$ \\
\hline WVAR & -0.0004 & -0.0005 & 0.0301 \\
\hline & $(4.03)$ & $(3.82)$ & $(15.12)$ \\
\hline MVAR & -0.0003 & -0.0006 & 0.0267 \\
\hline & $(3.94)$ & $(4.42)$ & $(13.86)$ \\
\hline QVAR & -0.0003 & -0.0007 & 0.0287 \\
\hline & $(3.80)$ & $(4.82)$ & $(13.38)$ \\
\hline
\end{tabular}

Panel B. Log specification

\begin{tabular}{cccc}
\hline & $\begin{array}{c}\text { REPO/VOLUME } \\
(1)\end{array}$ & $\begin{array}{c}\text { AGE } \\
(2)\end{array}$ & $\begin{array}{c}\text { KZ3 } \\
(3)\end{array}$ \\
\hline DVAR & -0.0025 & -0.0031 & 0.1426 \\
\hline & $(3.09)$ & $(3.60)$ & $(17.68)$ \\
\hline WVAR & -0.0027 & -0.0041 & 0.1536 \\
\hline & $(2.91)$ & $(3.77)$ & $(20.22)$ \\
\hline MVAR & -0.0027 & -0.0047 & 0.1573 \\
\hline & $(2.83)$ & $(4.08)$ & $(18.96)$ \\
\hline QVAR & -0.0027 & -0.0052 & 0.1609 \\
\hline & $(2.84)$ & $(5.10)$ & $(19.31)$ \\
\hline
\end{tabular}

Panel C. Three-year variance

\begin{tabular}{cccc}
\hline & REPO/VOLUME & AGE & KZ3 \\
$(1)$ & $(2)$ & $(3)$ \\
\hline DVAR & -0.0007 & -0.0001 & 0.0299 \\
\hline & $(2.05)$ & $(1.32)$ & $(8.10)$ \\
\hline WVAR & -0.0005 & -0.0004 & 0.0248 \\
\hline & $(2.14)$ & $(2.44)$ & $(9.17)$ \\
\hline MVAR & -0.0005 & -0.0005 & 0.0231 \\
\hline & $(2.06)$ & $(2.59)$ & $(7.35)$ \\
\hline QVAR & -0.0005 & -0.0006 & 0.0235 \\
\hline & $(2.12)$ & $(3.45)$ & $(9.72)$ \\
\hline
\end{tabular}

Panel D. US stock market before and after the regulatory reforms of 1982 (REPO/MKT and KZ)

\begin{tabular}{ccc}
\hline & $\begin{array}{c}\text { REPO/MKT } \\
(1)\end{array}$ & $\begin{array}{c}\text { KZ } \\
(2)\end{array}$ \\
\hline DVAR & & \\
\hline Constant & -0.0450 & 0.0249 \\
\hline & $(3.46)$ & $(6.40)$ \\
\hline AFTER82 & -0.2825 & 0.0168 \\
\hline & $(2.84)$ & $(4.18)$ \\
\hline
\end{tabular}




\begin{tabular}{|c|c|c|}
\hline WVAR & & \\
\hline \multirow[t]{2}{*}{ Constant } & -0.0596 & 0.0216 \\
\hline & $(8.46)$ & $(7.09)$ \\
\hline \multirow[t]{2}{*}{ AFTER82 } & -0.2225 & 0.0095 \\
\hline & $(2.61)$ & $(2.91)$ \\
\hline \multicolumn{3}{|l|}{ MVAR } \\
\hline \multirow[t]{2}{*}{ Constant } & -0.0410 & 0.0194 \\
\hline & (5.24) & $(7.26)$ \\
\hline \multirow[t]{2}{*}{ AFTER82 } & -0.2211 & 0.0092 \\
\hline & $(2.65)$ & $(2.99)$ \\
\hline \multicolumn{3}{|l|}{ QVAR } \\
\hline \multirow[t]{2}{*}{ Constant } & -0.0325 & 0.0223 \\
\hline & $(4.29)$ & $(6.74)$ \\
\hline \multirow[t]{2}{*}{ AFTER82 } & -0.2401 & 0.0072 \\
\hline & $(3.08)$ & $(2.00)$ \\
\hline
\end{tabular}

Panel E. International evidence - Log specification

\begin{tabular}{ccc}
\hline & $\begin{array}{c}\text { MVAR } \\
(1)\end{array}$ & $\begin{array}{c}\text { QVAR } \\
(2)\end{array}$ \\
\hline KZ3 & & \\
\hline EASYxKZ3 & 0.1584 & 0.1659 \\
\hline & $(12.86)$ & $(12.48)$ \\
\hline MEDIUMxKZ3 & 0.0120 & 0.0032 \\
\hline DIFFICULTxKZ3 & $(1.07)$ & $(0.29)$ \\
\hline & -0.1359 & -0.1540 \\
\hline KZ & $(3.35)$ & $(3.45)$ \\
\hline EASYxKZ & 0.1529 & 0.1600 \\
\hline MEDIUMxKZ & $(13.60)$ & $(13.25)$ \\
\hline & 0.0113 & 0.0031 \\
\hline DIFFICULTxKZ & $(1.06)$ & $(0.28)$ \\
\hline & -0.1099 & -0.1231 \\
\hline & $(2.91)$ & $(2.94)$ \\
\hline
\end{tabular}

Panel F. International evidence - Three-year variance

\begin{tabular}{ccc}
\hline & $\begin{array}{c}\text { MVAR } \\
(1)\end{array}$ & $\begin{array}{c}\text { QVAR } \\
(2)\end{array}$ \\
\hline KZ3 & & \\
\hline EASYxKZ3 & 0.0258 & 0.0261 \\
\hline MEDIUMxKZ3 & $(6.77)$ & $(6.06)$ \\
\hline & 0.0124 & 0.0125 \\
\hline DIFFICULTxKZ3 & $(3.21)$ & $(2.72)$ \\
\hline & -0.0272 & -0.0332 \\
\hline KZ & $(1.87)$ & $(2.14)$ \\
\hline EASYxKZ & 0.0283 & 0.0289 \\
\hline MEDIUMxKZ & $(7.78)$ & $(7.13)$ \\
\hline DIFFICULTxKZ & 0.0119 & 0.0120 \\
\hline & $(3.23)$ & $(2.73)$ \\
\hline
\end{tabular}


Table 7: Stock Return Skewness and Financing Constraint, U.S. Stock Market

Panel A of this table reports the Fama-MacBeth regression results of daily stock return skewness on financing constraint measures. CONSTRAINT is given by the following three financing constraint proxies. REPO/VOLUME is firm repurchases to daily dollar trading volume. AGE is the number of years a stock has price data in CRSP monthly file which starts in 1925. KZ3 is the Kaplan-Zingales index of financing constraints net of book leverage and firm market-to-book ratio. LOGSIZE is log market capitalization. MLEV is market leverage. LOGMB is log market-tobook ratio. RET is average monthly return in a year. TURNOVER is monthly turnover. The regressions include FamaFrench (1997) industry dummies and exchange dummies for NASDAQ and AMEX. The sample period is 1971-2005 for REPO/VOLUME and 1963-2005 for AGE and KZ3. Newey-West (1987) t-statistics are in the parentheses. Panel B of this table reports the results of a time-series regression using the coefficients in front of CONSTRAINT in Panel A. These coefficients are regressed on a constant and a dummy variable AFTER82 that equals one if the year of the crosssectional regression is after 1982 and zero otherwise. Newey-West (1987) t-statistics with twelve lags are in parentheses.

Panel A: Return skewness and financing constraint

\begin{tabular}{cccc}
\hline & $\begin{array}{c}\text { REPO/VOLUME } \\
(1)\end{array}$ & $\begin{array}{c}\text { AGE } \\
(2)\end{array}$ & $\begin{array}{c}\text { KZ3 } \\
(3)\end{array}$ \\
\hline CONSTRAINT & 0.0014 & 0.0011 & -0.0360 \\
\hline & $(3.43)$ & $(0.76)$ & $(2.47)$ \\
\hline LOGSIZE & -0.1207 & -0.1078 & -0.1084 \\
\hline & $(6.21)$ & $(4.80)$ & $(4.75)$ \\
\hline MLEV & -0.0842 & -0.0653 & -0.0069 \\
\hline LOGMB & $(4.51)$ & $(2.88)$ & $(0.18)$ \\
\hline & -0.0540 & -0.0690 & -0.0739 \\
\hline RET & $(2.11)$ & $(3.67)$ & $(3.07)$ \\
\hline TURNOVER & -0.8879 & -0.7948 & -0.7996 \\
\hline & $(6.35)$ & $(8.40)$ & $(6.20)$ \\
\hline & -1.0080 & -0.7269 & -0.7753 \\
\hline
\end{tabular}

Panel B: US stock market before and after the regulatory reforms of 1982

\begin{tabular}{cccc}
\hline & $\begin{array}{c}\text { REPO/VOLUME } \\
(1)\end{array}$ & $\begin{array}{c}\text { AGE } \\
(2)\end{array}$ & $\begin{array}{c}\text { KZ3 } \\
(3)\end{array}$ \\
\hline DSKEW & & & \\
\hline Constant & 0.0008 & 0.0005 & -0.0154 \\
\hline & $(2.94)$ & $(0.87)$ & $(2.38)$ \\
\hline AFTER82 & 0.0010 & 0.0012 & -0.0424 \\
\hline & $(2.15)$ & $(0.36)$ & $(2.84)$ \\
\hline
\end{tabular}

